\title{
Optimization of an Encapsulated Phase Change Material Thermal Energy Storage System
}

\author{
K. Nithyanandam and R. Pitchumani* \\ Advanced Materials and Technologies Laboratory \\ Department of Mechanical Engineering \\ Virginia Tech \\ Blacksburg, Virginia 24061-0238
}

\begin{abstract}
Thermal energy storage enables uninterrupted operation of a concentrating solar power (CSP) plant during periods of cloudy or intermittent solar availability. This paper presents a transient computational analysis of an encapsulated phase change material (EPCM) thermal energy storage (TES) system for repeated charging and discharging cycles to investigate its dynamic response. The influence of the design and operating parameters on the dynamic charge and discharge performance of the system is analyzed to identify operating windows that satisfy technoeconomic targets of storage cost less than $\$ 15 / \mathrm{kWh}_{\mathrm{t}^{\prime}}$ round-trip exergetic efficiency greater than 95\%, charge time less than 6 hours and a minimum discharge period of 6 hours. Overall, this study illustrates a methodology for design and optimization of encapsulated PCM thermal energy storage system (EPCM-TES) for a CSP plant operation.
\end{abstract}

Keywords: Thermal Energy Storage; Encapsulated Phase Change Materials; Concentrating Solar Power; Design Window; Optimization.

\section{Introduction}

Thermal energy storage system is essential to make concentrating solar power (CSP) generation competitive for meeting current and future energy needs. Storing energy for future use allows the power plant to operate continuously during periods of intermittent sun, reduces the mismatch between the energy supply and demand by providing load leveling and helps to conserve energy by improving the reliability and performance of CSP plants. Thermal energy can be stored as either sensible or latent heat [1]. Most of the thermal energy storage systems in

*Corresponding author; Phone: +1 540231 1776; E-mail: pitchu@vt.edu 
operation are based on sensible heat storage. Storing heat in the form of latent heat of fusion of phase change material (PCM) in addition to sensible heat significantly increases the energy storage capacity and reduces size of the TES system. However, a major technology barrier that is limiting the use of latent thermal energy of PCM is the higher thermal resistance provided by its intrinsically low thermal conductivity, thus requiring large heat transfer surface area of interaction. Several techniques to improve the thermal performance of latent thermal energy storage systems are reported in the literature; notable among them are embedding heat pipes or thermosyphons between the HTF and PCM [2-5], dispersing high conductivity particles in the PCM [6] and storing PCM within the framework of porous metal foams [7,8]. A review of various techniques employed to enhance the performance of high temperature latent thermal energy storage system is discussed in Ref. [9]. One promising approach is to increase the heat transfer area between the HTF and PCM by incorporating the PCM mixture in small capsules $[10,11,12]$.

Several reports on the numerical modeling of sensible heat storage in packed beds are found in the literature [13-20]. Ismail and Henriquez [21] presented a mathematical model for predicting the thermal performance of cylindrical storage tank containing spherical capsules filled with water as PCM. The model was used to investigate the influence of the working fluid inlet temperature, flow rate and the material of spherical capsules of fixed $(77 \mathrm{~mm})$ diameter on the solidification process. Felix Regin et al. [22] and Singh et al. [23] presented a brief review of the works performed in the thermocline storage system till date. Felix Regin et al. [24] also reported the modeling of thermocline energy storage system with embedded PCM capsules. Wu and Fang [25] analyzed the discharging characteristics of a solar heat storage system with a packed bed of spherical capsules filled with myristic acid as PCM. The influence of HTF mass flow rate, inlet temperature and the porosity of packed bed were studied.

In developing thermal storage technologies, the exergetic efficiency is sought to be high to ensure that heat quality is maintained after storage [1]. Previous investigations focused on latent thermal energy storage systems have shown that cascading several PCMs in the order of their decreasing melt temperatures from the hot HTF inlet side can result in higher heat transfer rates, as well as improved exergetic efficiency due to a more uniform temperature difference between the hot and cold media [26,27]. For CSP systems to be cost-competitive with other sources of energy generation on the grid, without subsidy, the U.S. Department of Energy's SunShot Initiative calls for thermal energy storage systems to have round-trip exergetic 
efficiency greater than $95 \%$ and a storage capital cost less than $\$ 15 / \mathrm{kWh}_{\mathrm{t}}$ for a minimum (maximum) discharge (charge) period of $6 \mathrm{~h}[1,28]$. The optimal design of an EPCM-TES system that meets the above technoeconomic requirements is, therefore, of considerable significance, and forms the focus of the present study.

Although several articles on the thermocline tank packed with sensible filler materials are reported, relatively few works on the performance of an EPCM-TES system is found in the literature. To the authors' knowledge, a comprehensive study of the dynamic performance of the system subjected to constraints dictated by the power plant operation is lacking in the literature. To this end, the objective of the present study is to investigate the influence of the design and operating parameters on the dynamic energy and exergy performance of the EPCMTES system using the model developed by the authors in Ref. [10]. Based on the parametric studies and specified constraints on the minimum exergetic efficiency, maximum storage capital cost, minimum discharge time and maximum charge time [28], operating windows are identified as a function of the various design and operating parameters for cascaded and noncascaded EPCM-TES system. A further contribution of the study involves finding the optimum combination of design and operating parameters of the EPCM-TES system subject to the aforementioned constraints.

The paper is organized as follows: The mathematical model, as developed in Ref. [10], is introduced in the next section followed by a discussion of the results of the parametric studies in Section 3. Section 4 presents the optimization problem formulation followed by discussion of the optimization results.

\section{Numerical Analysis}

\subsection{Model Development}

Figure 1a illustrates the schematic of an EPCM-TES tank of height $H_{\mathrm{t}}$ and radius $R_{\mathrm{t}}$ packed with spherical capsules filled with PCM. For the sake of clarity in illustration, an ordered arrangement of capsules is depicted in Fig. 1a; however, in reality, the packing scheme may vary and the porosity of the packed bed for a fixed diameter of spherical capsules can range from $0.25-0.48$ [29]. The solid arrows indicate the direction of hot HTF during charging while the dotted arrows indicate the direction of cold HTF flow through the storage system during discharging. For a 2-PCM cascaded configuration, the total tank height is divided into two and the heights of the top and bottom zone are denoted by $H_{2, \mathrm{~T}}$ and $H_{2, \mathrm{~B}^{\prime}}$ respectively in Fig. 1a. 
Similarly, the height of top, middle and bottom zones in a 3-PCM cascaded EPCM-TES system are represented by $H_{3, T^{\prime}} H_{3, M}$ and $H_{3, B^{\prime}}$ respectively (Fig. 1a). The inner radius of the capsules, represented by $R_{c^{\prime}}$ is filled with PCM (shaded), while the thickness of the capsule wall is denoted by $b$, as depicted in Fig. 1b.

The non-dimensional governing energy equations for the HTF temperature, $\theta_{f}$, and the encapsulated PCM temperature, $\theta_{p}$, provided in [10] are as follows:

$$
\begin{gathered}
\varepsilon \frac{\partial \theta_{f}}{\partial t^{*}}+\operatorname{Re}_{H} P r_{f} \frac{\partial \theta_{f}}{\partial z^{*}}=\frac{\partial^{2} \theta_{f}}{\partial z^{* 2}}+\frac{3(1-\varepsilon)}{\left(R_{c}^{*}+b^{*}\right)^{3}} \times \frac{\theta_{p, r^{*}=R_{c}^{*}}-\theta_{f}}{\left\{\frac{b^{*}}{k_{w}^{*} \times R_{c}^{*} \times\left(R_{c}^{*}+b^{*}\right)}\right\}+\left\{\frac{2}{N u \times\left(R_{c}^{*}+b^{*}\right)}\right\}} \\
{\left[1+\psi \frac{\partial f_{L}\left(\theta_{p}\right)}{\partial \theta_{p}}\right] \frac{\partial \theta_{p}}{\partial t^{*}}=\frac{k_{p}^{*} N u_{c o n v}}{\lambda} \frac{\partial}{\partial r^{*}}\left(r^{* 2} \frac{\partial \theta_{p}}{\partial r^{*}}\right)}
\end{gathered}
$$

where the nondimensional parameters are defined as follows:

$$
\begin{gathered}
z^{*}=\frac{z}{H_{t}} ; r^{*}=\frac{r}{H_{t}} ; t^{*}=\frac{k_{f} t}{\rho_{f} c_{f} H_{t}^{2}} ; b^{*}=\frac{b}{H_{t}} ; R_{c}^{*}=\frac{R_{c}}{H_{t}} ; \theta_{f}=\frac{T_{f}-T_{C}}{T_{C}-T_{D}} ; \theta_{p}=\frac{T_{p}-T_{C}}{T_{C}-T_{D}} ; \\
\psi=\frac{h_{s l}}{c_{p}\left(T_{C}-T_{D}\right)} ; \lambda=\frac{\rho_{p} c_{p}}{\rho_{f} c_{f}} ; k_{w}^{*}=\frac{k_{w}}{k_{f}} ; k_{p}^{*}=\frac{k_{p}}{k_{f}} ; R e_{H}=\frac{\rho_{f} U H_{t}}{\mu_{f}} ; P r_{f}=\frac{\mu_{f} c_{f}}{k_{f}} ; \\
N u=\frac{h H_{t}}{k_{f}}=2+2.87\left[\left(R_{c}^{*}+b^{*}\right) R e_{H}\right]^{1 / 2} P r_{f}^{1 / 3}+0.098\left(R_{c}^{*}+b^{*}\right) R e_{H} P r_{f}^{1 / 2}
\end{gathered}
$$

The terms $\rho, c, k$ and $T$ correspond to density, specific heat, thermal conductivity, and temperature, respectively, of either the HTF denoted by subscript $f$ or the encapsulated PCM denoted by subscript $p, h_{\mathrm{sl}}$ denotes the latent heat of fusion of the PCM, $t$ denotes time, $U$ represents the superficial velocity of the heat transfer fluid entering the packed bed storage system, $h$ represents the convective heat transfer coefficient between the HTF and PCM capsules and $\varepsilon$ denotes the porosity of the packed bed. The convection Nusselt number, $N u_{\text {conv }}$ determines the effective thermal conductivity of the PCM due to the buoyancy driven convection currents during melting of the PCM, which is explained in detail in Ref. [10]. The interstitial Nusselt number, $N u$, thermally couples the HTF with the spherical PCM capsules. The fluid-particle heat transfer interaction in packed beds has been extensively studied and numerous correlations for the interstitial heat transfer coefficient exist in the literature [20]. In the present study, the interstitial Nusselt number is given by the above expression obtained from Galloway and Sage [30]. The validity of the expression is confirmed experimentally for the range of $R e_{H} \times\left(R_{c}^{*}+b^{*}\right)<2500$ [16]. The other characteristic nondimensional parameters that 
appear in Eq. (3) are the Reynolds number, $R e_{\mathrm{H}^{\prime}}$ Prandtl number of the HTF, $P r_{\mathrm{f}}$ and the inverse Stefan number of the PCM, $\psi$. Subscripts $C$ and $D$ correspond to the hot inlet HTF temperature during charging and the cold inlet HTF temperature during discharging, respectively. Note that hot HTF enters the tank at $z^{*}=0$ during charging and the exit temperature of the HTF corresponds to an axial position of $z^{*}=1$ and vice-versa during discharge.

Further, the boundary conditions during the charging and discharging process are specified as

$$
\begin{gathered}
\theta_{f}\left(z^{*}=0\right)=1, \frac{\partial \theta_{f}}{\partial z^{*}}\left(z^{*}=1\right)=0 ; \text { Charging } \\
\theta_{f}\left(z^{*}=1\right)=0, \frac{\partial \theta_{f}}{\partial z^{*}}\left(z^{*}=0\right)=0 ; \text { Discharging } \\
k_{p}^{*} \frac{\partial \theta_{p}}{\partial r^{*}}\left(r^{*}=R_{c}^{*}, 0<z^{*}<1\right)=\frac{\left[\theta_{p}\left(R_{c}^{*}, z^{*}\right)-\theta_{f}\left(z^{*}\right)\right] / R_{c}^{*}}{\left[\left\{\frac{b^{*}}{k_{w}^{*} \times\left(R_{c}^{*}+b^{*}\right)}\right\}+\left\{\frac{2 \times R_{c}^{*}}{N u \times\left(R_{c}^{*}+b^{*}\right)}\right\}\right]} \\
\frac{\partial \theta_{p}}{\partial r^{*}}\left(r^{*}=0,0<z^{*}<1\right)=0
\end{gathered}
$$

The numerical simulations start with a charge process assuming that the tank is completely discharged initially, resulting in the following initial conditions for the HTF and the PCM phase:

$$
\theta_{f}=0 ; \theta_{p}=0
$$

The complete set of governing equations is discretized using the finite volume approach and the melting/solidification of the PCM is modeled using the fixed-grid enthalpy-porosity method as presented by Voller et al. [31]. In the fixed grid enthalpy-based formulation, the liquid fraction in each computational cell, in conjunction with the temperature, $\theta_{p^{\prime}}$ predicted by Eq. (2) for the encapsulated PCM, is updated based on the enthalpy balance at each iteration within a time step. The liquid fraction $f_{L}\left(\theta_{p}\right)$ is given by the Heaviside step function at $\theta_{p}=\theta_{m}$, represented as $f_{L}=0, \theta_{p}<\theta_{m}$ and $f_{L}=1, \theta_{p}>\theta_{m}$, where $\theta_{m}$ is the melt temperature of PCM. The region between $f_{\mathrm{L}}=0$ to 1 , termed the mushy zone, is modeled as a pseudo-porous medium, in which the porosity increases from 0 to 1 as the PCM absorbs latent heat at a constant temperature and melts. In the present case, the enthalpy iterative updating scheme of the liquid fraction takes the following form for a pure PCM, which melts at constant temperature:

$$
\psi f_{L(i)}^{n+1}=\psi f_{L(i)}^{n}+\frac{a_{i}}{a_{i}^{0}} \delta\left[\theta_{p(i)}^{n}-F^{-1}\left(f_{L(i)}^{n}\right)\right]
$$


In the above equation, $a_{\mathrm{i}}$ is the coefficient of $\theta_{p(i)}$ for the radial nodal point $i$ in the discretized energy equation of the PCM, $n$ is the iteration number, $\delta$ is a relaxation factor, which is set to 0.01 for the present case, and $F^{-1}$ is the inverse of latent heat function which takes the value of $\theta_{m}$ for a pure substance.

The coupled system of governing equations in their nondimensional form is solved using an implicit method with the diffusive and convective fluxes discretized using hybrid differencing scheme, the convective-diffusive fluxes in the HTF governing equation (Eq. (1)) discretized using the power-law scheme, and the diffusive fluxes in the PCM governing equation (Eq. (2)) discretized using central differencing scheme [32]. After a systematic grid refinement study, the EPCM-TES tank was discretized into 200 equally spaced intervals in the axial direction and the encapsulated PCM within the spherical capsules was discretized into 10 uniform zones in the radial direction. The nondimensional time step chosen for the study was $\Delta t^{*}=1.25 \times 10^{-9}$. The iterative residuals at each time step are converged to the order of $10^{-9}$ to eliminate iterative errors from the solution.

\subsection{Performance Metrics}

Since a thermal storage system installed in a CSP plant is subjected to repeated charging and discharging processes, the dynamic behavior of the EPCM-TES system is analyzed in the present study. Initially, the tank is kept in a fully discharged state as established by Eq. (5) and charging takes place as hot HTF flows into the tank from the top (Fig. 1a) until the temperature of the HTF flowing out of the storage system reaches a certain maximum charging cut-off temperature, $\theta_{C}^{\prime}$. Now, during the subsequent discharge process, cold HTF enters from the bottom of the tank (Fig. 1a) and discharge process continues until the exit temperature of the HTF flowing out from the top of the tank reaches a minimum discharge cut-off temperature, $\theta_{D}^{\prime}$.

Commonly in CSP plants, the HTF exiting the storage tank during discharge (charge) is fed into the power block (receiver) for superheat steam generation (solar energy capture). The material temperature limitations of the heat transfer fluid and the solar receiver dictate a maximum cut-off temperature, $\theta_{C}^{\prime}$, for the HTF exit temperature of the thermocline system during charging. If the exit temperature exceeds this value, a high flow rate is needed through the receiver in order to keep the temperature of HTF in the receiver within allowable limits. The high flow rate, in turn, increases parasitic and thermal losses [33]. Similarly, the strong dependence of the power block Rankine cycle efficiency on the incoming HTF temperature [33] 
requires the termination of discharge process when the HTF exit temperature reaches a certain minimum dimensionless discharge cut-off temperature, $\theta_{D}^{\prime}$. The combined charge and discharge process is referred to as one cycle. In the present study, $\theta_{C}^{\prime}$ and $\theta_{D}^{\prime}$ are selected to be 0.39 and 0.74, respectively, representative of restrictions imposed on molten salt power tower CSP plant operation [33]. Since the dynamic behavior of the storage system subjected to partial charge and discharge process is of primary interest to the designer, repeated charging and discharging process are carried out until a periodic state is achieved. The performance of the EPCM-TES system is analyzed following repeated charge and discharge processes until a periodic state is established, when the variations in output and performance metrics from one cycle to another are negligible (less than $0.002 \%$ ). It is to be noted that repeated charging and discharging processes with large temperature oscillations throughout the filler bed and tank wall may result in a build-up of undesirable mechanical stress in the tank shell. Structural failure of the tank occurs if the stresses in the tank shell exceed the yield strength of the shell material, a condition known as thermal ratcheting. However, Flueckiger et al. [34], through comprehensive numerical analysis, has shown that thermal ratcheting is not an issue and is not explored in the present study.

The cyclic exergetic efficiency of the EPCM-TES system defined as the ratio of exergy recovered by the HTF during discharging to the exergy gained by the HTF during charging of each cycle [1]:

$$
\zeta=\frac{\int_{t_{C}}^{t_{D}}\left[T_{f}(z=0, t)-T_{D}-T_{r e f} \cdot \ln \left(\frac{T_{f}(z=0, t)}{T_{D}}\right)\right] \cdot d t}{\int_{0}^{t}\left[T_{C}-T_{f}\left(z=H_{t}, t\right)-T_{r e f} \cdot \ln \left(\frac{T_{C}}{T_{f}\left(z=H_{t}, t\right)}\right)\right] \cdot d t}
$$

where $T_{\text {ref }}$ is the reference or ambient temperature, which is assumed to be $300 \mathrm{~K}$ [1] in the present analysis. The term, $T_{\mathrm{f}}(z=0, t)$ in the numerator refers to the exit temperature of the HTF at the top of the EPCM-TES tank during discharging while the term $T_{\mathrm{f}}\left(z=H_{\mathrm{t}}, t\right)$ in the denominator refers to the temperature of the HTF at the bottom of the EPCM-TES system, which is the outlet for charging. The exergetic efficiency cannot be calculated in terms of nondimensional variables because the logarithmic term in the denominator always tends to infinity, since the nondimensional variable of $T_{D^{\prime}}$ viz. $\theta_{D}$ as defined in Eq. (3) equals zero. Hence the charge $\left(T_{C}\right)$ and discharge $\left(T_{D}\right)$ temperatures for the calculation of exergetic efficiency are considered to be $574 \mathrm{C}$ and $290 \mathrm{C}$, respectively [33], typical of molten salt power tower operation. 
The outputs from the model comprise the transient axial variation of temperature in the $\mathrm{HTF}$, the transient radial variation of temperature and the melt fraction of PCM within the capsule at any axial location. The nondimensional operating and design parameters investigated in the present study and the corresponding default values are presented in Table 1. The other default values pertain to $b^{*}=5 \times 10^{-8} ; \operatorname{Pr}_{\mathrm{f}}=5 ; k_{w}^{*}=1 ; k_{p}^{*}=1$ and $\varepsilon=0.25$. The nondimensional height of each individual zone in cascaded configuration is defined as $H_{p, q}^{\prime}=H_{p, q} / H_{t}$, where $p$ denotes the number of cascades and subscript $q$ denotes either $T$ (top zone), $M$ (middle zone) or $B$ (bottom zone). The range for each of the operating and design parameters included in the present study is determined from a literature review of various PCM properties [9,35] and molten salt HTF properties [33]. Numerical simulations were conducted for various combinations of the aforementioned design and operating parameters to analyze its effect on the charge time, discharge time and exergetic efficiency of the EPCM-TES system at its periodic steady state. It was shown in [10] that the periodic state is achieved beyond the fourth cycle and accordingly, the values from the simulation during the fifth cycle are presented as being the periodic state results. For instance, Table 2 shows the results obtained for cycles 1 to 15 for default 3-PCM cascaded EPCM-TES system configuration. The variations in the performance metrics between the current and preceding cycle are presented in brackets. It is observed that the charge and discharge times equilibrated to a periodic steady state value by the end of fifth cycle. Negligible variations in the exergetic efficiency are observed beyond the fifth cycle. However, the selection of $0.002 \%$ as the periodic state (cycle 5) is justifiable as the relative difference in the exergetic efficiency values between cycle 5 (97.0152\%) and cycle 15 $(97.01381 \%)$ is only $1.4 \times 10^{-5}$, which is well within the numerical tolerance limits.

The validation of the model is presented in Ref. [10] and is not repeated here in the interest of brevity. The numerical model presented in this section forms the basis of the parametric studies discussed in Section 3 and is also used in a numerical optimization of the EPCM-TES system as formulated in Section 4. In the following section, references to the design and operating parameters correspond to the nondimensional parameters, unless stated otherwise.

\section{Results and Discussion}

\subsection{Parametric Studies}

The effect of the various design and operating parameters on the performance of the EPCMTES system is studied by varying one parameter at a time with the rest of the parameters at the 
default value presented in Table 1.

Figure $2 \mathrm{a}-\mathrm{d}$ illustrates the effect of the nondimensional parameters on the various performance metrics of the storage system namely, the charge time, discharge time and exergetic efficiency for a non-cascaded EPCM-TES system. The variations in charge time are represented by lines with markers, while the lines without markers denote the variations in discharge time. From Fig. 2a, it is observed that charge time and discharge time decreases with increase in Reynolds number and capsule radius due to the shorter residence time of the incoming HTF with increase in $R e_{\mathrm{H}}$ for effective heat exchange between the HTF and PCM, and increase in thermal conduction resistance in the PCM with increase in $R_{c}^{*}$, respectively. The decrease in the discharge time is more pronounced than the decrease in charge time with increase in capsule radius, due to the conduction dominated solidification of PCM during discharge, in contrast to the buoyancy-driven convection assisted melting of PCM during charging. Figure $2 b$ illustrates the effect of capsule radius and Reynolds number on the exergetic efficiency of the system. It is observed that for a capsule radius of $R_{c}^{*}=0.00025$, characterized by small thermal conduction resistance for heat transfer from the HTF to PCM, the influence of Reynolds number on the exergetic efficiency is not pronounced. As the capsule radius increases, the conduction resistance within the PCM capsules increases resulting in a slower extraction of both latent and sensible energy from the interior of PCM capsules. In addition, the shorter residence time of the incoming HTF with increase in $R e_{\mathrm{H}}$ leads to a faster decrease of the HTF exit temperature $\left(\theta_{f}\right.$ at $\left.z^{*}=0\right)$ during the discharge process of larger capsule radius, thus resulting in a decrease of exergetic efficiency with increase in $R e_{\mathrm{H}}$ and $R_{c}^{*}$.

The effect of capacitance ratio on the charge time, discharge time and exergetic efficiency of the EPCM-TES system are illustrated in Fig. 2c and d. For a given Reynolds number, the charge time and discharge time is found to increase with increase in capacitance ratio (Fig. 2c) due to the increase in volumetric heat capacity of the system. The same observations are found with exergetic efficiency, although the roles are reversed, in that it is found that exergetic efficiency is greater for system with smaller capacitance ratio (Fig. 2d). This is attributed to the fact that even though the charge and discharge times are longer for a higher capacitance ratio, concomitant with increase in storage capacity, the HTF exit temperature during discharge $\left(\theta_{f}\right.$ at $\left.z^{*}=0\right)$ for system with higher capacitance ratio will be at the PCM melt temperature $\left(\theta_{m}=0.75\right)$ for longer duration of the discharge process, which is less than the highest temperature $\left(\theta_{f}=1\right)$, due to the higher thermal inertia compared to the system with smaller capacitance ratio. This implies a 
decrease in the quality of energy being delivered to the power block, reflecting a decrease in the exergetic efficiency. Nevertheless, the decrease in exergetic efficiency with increase in capacitance ratio is inconsequential as depicted in Fig. 2d. For the chosen default PCM melt temperature of 0.75 , the driving force for PCM solidification, $\Delta \theta_{D}=\theta_{m}-\theta_{D}$ is higher compared to that for PCM melting, $\Delta \theta_{C}=\theta_{C}-\theta_{m}$. This leads to an efficient heat exchange between the HTF and PCM during the discharge process and hence, a gradual decrease in the exit temperature of the HTF. This results in a longer discharge time compared to the charge time for the results presented in Fig. 2a and c.

Figure $3 a-c$ illustrates the variations in charge time, discharge time and exergetic efficiency with Reynolds number for various PCM melt temperatures. For any given Reynolds number, the charge and discharge time is found to be significantly higher for PCM with $\theta_{m}$ either between $0 \leq \theta_{m} \leq \theta_{C}^{\prime}$ or between $\theta_{D}^{\prime} \leq \theta_{m} \leq 1$ (Fig. 3a and b). The charge time in Fig. 3a is found to increase from $\theta_{m}=0.0$ to $\theta_{m}=0.39$, which is the charging cut-off temperature $\left(\theta_{C}^{\prime}\right)$. This can be explained by the fact that the driving force for PCM melting which manifests as the temperature difference between the incoming hot HTF and the PCM melt temperature $\left(\Delta \theta_{C}=\theta_{C}-\theta_{m}\right)$ decreases, leading to slower charge rate. For $\theta_{m}=0.0$, discharge process does not lead to PCM solidification and hence the EPCM-TES system works only in the sensible regime during the cyclic operation. This is also confirmed by calculating the latent utilization of the system, defined as the amount of latent energy extracted from the system to the total latent energy capacity of the system [10], which amounts to zero. A detailed explanation of the parametric effects on the utilization of the EPCM-TES system can be found in Ref. [10]. The aforementioned reason also applies for $\theta_{m}=1.0$, with the only difference being no driving force exists for PCM melting during charge process, thereby leading to a slight decrease in the charge time with increase in PCM temperature from $\theta_{m}=0.74$, which is the discharging cut-off temperature $\left(\theta_{D}^{\prime}\right)$, to $\theta_{m}=1$. It is seen that for $\theta_{C}^{\prime}<\theta_{m}<\theta_{D}^{\prime}$, the charge time, as depicted in Fig. 3a, is faster due to insignificant system utilization. As explained in Ref. [10], the latent energy utilization of the EPCM-TES system for PCM melt temperature in the range $\theta_{C}^{\prime}<\theta_{m}<\theta_{D}^{\prime}$, is found to be the least with only a portion of the PCM adjoining the capsule wall involved in the phase change process and the EPCM-TES system is in operation only for a short duration due to faster approach of cut-off temperatures.

Comparing Fig. 3a and b, it is seen that the discharge time trends follow a mirror image of the trends observed for the charge time about the ordinate axis. Hence, from Fig. 3a and b, it can 
be observed that charge time is maximum at $\theta_{m}=0.38$ while the discharge time is maximum at $\theta_{m}=0.75$ for any given Reynolds number. As PCM melt temperature increases from $0.74\left(\theta_{D}^{\prime}\right)$ to 1, the temperature difference between the incoming cold HTF and the PCM melt temperature driving the PCM solidification increases, thus leading to faster discharge time. The slight decrease in discharge time from $\theta_{m}=0.39$ to $\theta_{m}=0$ is attributed to the decreasing drive force for the solidification of PCM during discharging, and the discharging cut-off temperature is attained faster. The exergetic efficiency is higher for PCMs with melt temperatures of either 0 or 1 (Fig. 3c) because of operation in the sensible regime accompanied by almost equal charge and discharge time (Fig. 3a and b). For PCM with melt temperature between $\theta_{C}^{\prime}$ and $\theta_{D}^{\prime}$, the exergetic efficiency is relatively high, as clearly seen from Fig. 3c, because of similar reason stated for PCM melt temperatures of 0 and 1, in that, sensible energy transfer between the HTF and PCM takes place predominantly compared to latent energy transfer. Within the PCM melt temperature range, $\theta_{D}^{\prime} \leq \theta_{m}<1$, the HTF exiting the tank during the discharge process remains at the PCM melt temperature for longer duration and as the PCM melt temperature increases from $\theta_{D}^{\prime}$ to 1 , the quality of energy (exergetic efficiency) fed to the power block increases. The exergetic efficiency increases as the PCM melt temperature decreases from $\theta_{C}^{\prime}$ to zero, because the EPCM-TES system approaches sensible energy operation mode. Even though the exergetic efficiency of PCM's with melt temperatures in the feasible operating range, namely $0<\theta_{m} \leq \theta_{C}^{\prime}$ and $\theta_{D}^{\prime} \leq \theta_{m}<1$, is lesser than the rest, it is to be noted that the exergetic efficiency is still greater than the $95 \%$ target considered here. Also, from Fig. 3a-c, it can be observed that charge time, discharge time and exergetic efficiency, respectively, for any given PCM melt temperature decreases with increase in Reynolds number due to the shorter residence time of the incoming HTF.

Figure $3 d-f$ portrays the various performance metrics of the EPCM-TES system as a function of $R e_{\mathrm{H}}$ for different inverse Stefan number, $\psi$. With initial increase in inverse Stefan number, the charge and discharge time increases, due to increase in volumetric storage capacity of the EPCM-TES system. With further increase in inverse Stefan number, $\psi>0.25$, the latent thermal inertia of the system also increases, which results in a slower solidification of the PCM in the capsules and a meager increase in the charge and discharge times are observed in Fig. $3 \mathrm{~d}$ and e, respectively. Comparing Fig. $3 \mathrm{~d}$ and e, it can be inferred that the effect of inverse Stefan number on the increase in charge time for $\psi>0.25$ is less pronounced than on discharge time. It is primarily due to the fact that the default PCM melt temperature value chosen $\left(\theta_{m}=0.75\right)$ leads 
to slower PCM melting due to weaker driving force for melting $\left(\Delta \theta_{C}=\theta_{C}-\theta_{m}\right)$. This limits the heat exchange rate between the HTF and PCM resulting in faster approach of the charge cut-off temperature, notwithstanding the increase in volumetric storage capacity with increase in inverse Stefan number. For the same reason, the charge time in Fig. $3 \mathrm{~d}$ is found to be faster than the discharge time in Fig. 3e, except for the inverse Stefan number of zero for which the charge and discharge times are approximately the same. It is to be noted that an inverse Stefan number of zero conforms to a sensible thermocline storage system, for which the PCM melt temperature has no influence, resulting in equal charge and discharge times. For any given Reynolds number, it is found from Fig. 3f that the exergetic efficiency decreases with increase in inverse Stefan number. At higher inverse Stefan number, longer discharge time at the PCM melt temperature, which is lesser than the highest temperature $\left(\theta_{C}=1.0\right)$ leads to larger exergy destruction and hence reduced exergetic efficiency.

From previous plots, it is observed that the exergetic efficiency for almost all of the parametric values are greater than $95 \%$ which was also verified for other parametric combinations and hence is not illustrated further on. To this extent, Fig. $4 \mathrm{a}$ and $\mathrm{b}$ displays the effects of top zone PCM melt temperature and bottom zone PCM melt temperature, respectively, on the charge (with markers) and discharge (without markers) times of a 2-PCM cascaded EPCM-TES system configuration for various Reynolds number. From the variations of PCM melt temperature at the top zone (Fig. 4a), it is observed that the charge and discharge times are higher for PCMs with melt temperature greater than 0.74, which is the discharge cutoff temperature. However, it is seen that with subsequent increase beyond $\theta_{m, T}=0.75$ in PCM melt temperature at the top zone - for which the discharge time at $R e_{\mathrm{H}}=10000$ is $t_{D}^{*}=2.69 \times$ $10^{-5}$ compared to a discharge time of $t_{D}^{*}=2.45 \times 10^{-5}$ for $\theta_{m, T}=0.74-$ the discharge time decreases due to impediment in the melting of PCM as $\Delta \theta_{C}$ decreases. The same phenomena of the decrease in discharge time can be observed in Fig. 4b, although for temperatures below 0.39, due to the decrease in driving force for solidification as $\Delta \theta_{D}\left(\Delta \theta_{D}=\theta_{m}-\theta_{D}\right)$ decreases. It is also observed from Fig. $4 b$, that the discharge and charge times decrease and remains constant for PCM melt temperatures greater than $\theta_{m, B}=0.39$, which is the charging cut-off temperature, as observed for non-cascaded configuration in Fig. 3b. However, the magnitude of decrease in discharge and charge times as the PCM melt temperature in the bottom zone decreases from charging cut-off temperature to higher melt temperatures in the range $\theta_{C}^{\prime}<\theta_{m}<\theta_{D}^{\prime}$, is not as high as observed for a non-cascaded EPCM-TES system configuration (Fig. 3b) because of the 
fact that the PCM melt temperature at the top zone $\left(\theta_{m, T}=0.75\right)$ extends the system operation during discharge. As depicted in Fig. 4b, the charge time is greater than the discharge time only for bottom zone PCM melt temperature in the range 0.22 to 0.40 . For $\theta_{m, B}<0.22$, the thermal drive force for the melting of PCM $\left(\Delta \theta_{C}=\theta_{C}-\theta_{m}\right)$ increases, leading to a steeper increase in the HTF exit temperature during charging $\left(\theta_{f}\right.$ at $\left.z^{*}=1\right)$ and faster attainment of the charging cut-off temperature $\left(\theta_{C}^{\prime}\right)$. The charge time in Fig. $4 \mathrm{~b}$ is observed to be lesser than the discharge time for $\theta_{m, B}>0.39$, as the PCM melt temperature close to the exit port for charging $\left(z^{*}=1\right)$ falls outside the charging cut-off temperature constraint. The charge time in Fig. 4a is found to be higher than the discharge time for all the top zone PCM melt temperature, because the default PCM melt temperature in the bottom zone at $\theta_{m, B}=0.25$, which is within the range $0 \leq \theta_{m} \leq$ $\theta_{C}^{\prime}$, results in a gradual increase in the exit temperature of the HTF $\left(\theta_{f}\right.$ at $\left.z^{*}=1\right)$ and longer charge time to attain $\theta_{C}^{\prime}$.

Figure 4c shows the effect of varying the height of the top zone in a 2-PCM cascaded EPCMTES system, $H_{2, T}^{\prime}$ on the overall performance of the EPCM-TES system. At $H_{2, T}^{\prime}=1$, the EPCMTES system is packed with PCM undergoing solid-liquid phase change at $\theta_{m}=0.75$ leading to a longer (shorter) discharge (charge) time compared to the shorter (longer) discharge (charge) time obtained for $H_{2, T}^{\prime}=0$, when the EPCM-TES system is packed with PCM having a melt temperature of $\theta_{m}=0.25$, for any given Reynolds number. This is attributed to the higher solidification (melting) driving force for $H_{2, T}^{\prime}=1\left(H_{2, T}^{\prime}=0\right)$, which results in an efficient heat exchange between the HTF and PCM, thus leading to a longer discharge (charge) time. Figure $4 c$ shows that as the zone height increases, the charge and discharge times increase until $H_{2, T}^{\prime}=0.5$ (equally divided zones) after which it decreases as the system configuration tends to a non-cascaded EPCM-TES system configuration at $H_{2, T}^{\prime}=1$. For instance at $R e_{\mathrm{H}}=10000$, the discharge time of ECPM-TES system is $t_{D}^{*}=2.69 \times 10^{-5}$ with $H_{2, T}^{\prime}=0.5$ and the total utilization of 2-PCM cascaded configuration is $82.95 \%$ with $98.39 \%$ of the energy coming from the latent enthalpy of fusion of the PCM, while the discharge time of non-cascaded configuration at $H_{2, T}^{\prime}=1.0$ is $t_{D}^{*}=2.29 \times 10^{-5}$ with a total utilization of $68.0 \%$ and a latent utilization of $38.84 \%$ only.

Figure 5a-c portrays the combined effects of Reynolds number and PCM melt temperature at the top, middle and bottom zone respectively, while Fig. $5 \mathrm{~d}-\mathrm{f}$ portrays the combined effects of Reynolds number and height of the top, middle and bottom zone, respectively on the charge and discharge times for a 3-PCM cascaded EPCM-TES system configuration. The variations in 
charge time are represented by lines with markers, while the lines without markers denote the variations in discharge time. In Fig. 5a, for the top zone default PCM melt temperature of $\theta_{m, T}=0.75$, the charge and discharge times are found to be the highest. For melt temperature just below the default, a step decrease in charge and discharge times are observed because the melt temperature falls outside the range, $\theta_{D}^{\prime} \leq \theta_{m, T} \leq 1$, leading to a faster attainment of the discharge and charge cut-off temperatures. For melt temperatures above the default value, $\theta_{D}^{\prime}<\theta_{m, T} \leq 1$, the charge and discharge times gradually decrease due to the decrease in driving force for melting as $\Delta \theta_{C}$ decreases. Figure $5 \mathrm{~b}$ shows that changing the PCM melt temperature at the middle zone does not significantly affect the charge and discharge times, although the maximum charge and discharge times are achieved for $\theta_{m, M}=0.5$. This is attributed to the fact that for equally divided 3-zone PCM cascaded configuration; PCM's with equally spaced intervals in melt temperatures lead to a more uniform temperature difference between the hot and cold media. It is observed from Fig. $5 b$ that the discharge time is higher than the charge time for PCM melt temperatures, $\theta_{m, M}>0.5$, as the thermal drive force for the melting of PCM $\left(\Delta \theta_{C}\right)$ decreases, leading to faster attainment of charge cut-off temperature. Figure $5 c$ exhibiting the variations in bottom zone PCM melt temperature shows that a step decrease in charge and discharge time is observed when the melt temperature falls outside the range, $0<\theta_{m, B} \leq \theta_{C}^{\prime}$. Within the temperature range of $0<\theta_{m, B} \leq \theta_{C}^{\prime}$, the charge and discharge time decreases gradually with decrease in melt temperature from $\theta_{C}^{\prime}$ to 0 due to the decrease in driving force for solidification as $\Delta \theta_{D}$ decreases. As observed for a 2-PCM cascaded configuration in Fig. $4 \mathrm{~b}$, the charge time is higher than the discharge time only for bottom-zone PCM melt temperatures between 0.22 and $0.39\left(\theta_{C}^{\prime}\right)$.

Since the height of each of the zones cannot be varied independently, in the present study, the heights of two zones are varied simultaneously to analyze its influence on the performance metrics. For instance in Fig. 5d, the nondimensional heights, as defined in Section 2.2, of the top zone and middle zone are varied simultaneously while the height of the bottom zone is fixed at the default value of 0.335 . Figure $5 \mathrm{~d}$ shows that as the top zone height increases from 0 to 0.2 , the charge and discharge times gradually increase while the increase is higher when the top zone height increases from 0.2 to 0335 . With a top zone height of 0 , the EPCM-TES system becomes a 2-PCM cascaded configuration with the nondimensional middle zone height of 0.667. Since the default PCM melt temperature of the middle zone is 0.5 , which falls outside the cut-off temperature ranges, $0 \leq \theta_{m}<\theta_{C}^{\prime}$ and $\theta_{C}^{\prime} \leq \theta_{m}<1$, the latent energy utilization of the PCM is 
restricted, and hence the charge and discharge times are the lowest for any given Reynolds number. As the height of the top zone filled with PCM of melt temperature 0.75 increaseswithin the limits of $\theta_{D}^{\prime} \leq \theta_{m}<1$, the discharge time increases and when the top zone height increases from 0.2 to 0.335 the discharge time increases drastically, for instance from $2.36 \times 10^{-5}$ to $2.89 \times 10^{-5}$ at $R e_{\mathrm{H}}=10000$, reflecting a uniformity in the temperature difference between the HTF and PCM leading to a better system utilization. However, the discharge time peaks at $H_{3, T}^{\prime}=0.467\left(H_{3, B}^{\prime}=0.200\right)$, for instance $t_{D}^{*}=2.92 \times 10^{-5}$ at $R e_{\mathrm{H}}=10000$, although the increase from $H_{3, T}^{\prime}=0.335$ is very subtle. The charge time followed the same trend as discharge time except that it peaked for a top zone height of $0.335\left(t_{C}^{*}=2.91 \times 10^{-5}\right.$ at $\left.R e_{\mathrm{H}}=10000\right)$ while it was the lowest for $H_{3, T}^{\prime}=0$ (Fig. 5d).

Similarly from Fig. 5e, it is found that the charge and discharge times are highest for middle zone height of 0.335 . It is to be noted that the observation is different from that portrayed in Fig. $5 \mathrm{~d}$, in that the highest discharge time was observed for a top zone height of 0.467 with a corresponding mid zone height of 0.2. While varying middle zone height to 0.2 in Fig. 5e, the top zone height remains at the default 0.335 and the bottom zone height is increased to 0.467, which is different from the analysis in Fig. 5d. From Fig. 5f, it is observed that for $H_{3, B}^{\prime}<0.335$, the charge and discharge times increase with simultaneous increase and decrease in bottom and top zone heights, respectively, due to the availability of PCM at melt temperatures between $0<\theta_{m} \leq \theta_{C}^{\prime}$ and $\theta_{D}^{\prime} \leq \theta_{m}<1$. The discharge time (Fig. 5f) is highest when the top and bottom zone heights are equally distributed $\left(H_{3, B}^{\prime}=0.335\right)$ implying the significance of having PCMs with melt temperature at both the low and high temperature range below the charging cut-off temperature and above the discharging cut-off temperature, respectively. The discharge time decreases with increase in $H_{3, B}^{\prime}>0.335$, due to the decrease in the top zone height filled with PCM melt temperature of 0.75 , thus resulting in quicker attainment of discharge cut-off temperature. Hence the charge time also decreases with increase in bottom zone height for $H_{3, B}^{\prime}>0.335$. The discharge time of a 3-PCM cascaded configuration with equally divided zone heights is higher $\left(t_{D}^{*}=2.89 \times 10^{-5}\right.$ for $\left.R e_{\mathrm{H}}=10000\right)$ compared to a 2-PCM cascaded configuration with equally divided zone heights $\left(t_{D}^{*}=2.69 \times 10^{-5}\right.$ for $\left.R e_{\mathrm{H}}=10000\right)$ while the discharge time of a non-cascaded configuration at the default parametric value is $t_{D}^{*}=2.29 \times$ $10^{-5}$ for $R e_{\mathrm{H}}=10000$. It is also observed from Fig. 5a-f that the charge (discharge) time decreases with increase in Reynolds number due to insufficient residence time of the incoming hot (cold) 
HTF within the tank, resulting in poor heat exchange between the HTF and EPCM, and faster decay of the HTF exit temperatures.

\subsection{Design Window}

The effects of the nondimensional parameters on the system performance, presented in Figs. 2-5, may be used to identify system design configurations that satisfy the technoeconomic targets of (1) discharge time greater than 6 hours, (2) charge time less than 6 hours, (3) exergetic efficiency greater than $95 \%$ and (4) storage cost less than $\$ 15 / \mathrm{kWh}$. To this extent, properties of molten salt $\left(60 \% \mathrm{NaNO}_{3}+40 \% \mathrm{KNO}_{3}\right)[10,33]$ and two different tank heights, $15 \mathrm{~m}$ and $20 \mathrm{~m}$, are considered for which the nondimensional time pertaining to 6 hours are $1.732 \times 10^{-5}$ and $0.9932 \times 10^{-5}$, respectively. In this study, design windows identifying regions that satisfy the technoeconomic targets $[1,28]$ are presented in the reminder of the section for a power tower CSP plant operating at a rated capacity of $115 \mathrm{MW}_{\mathrm{e}}$ within the temperature ranges of $290 \mathrm{C}\left(T_{\mathrm{D}}\right)$ and $574 \mathrm{C}\left(T_{\mathrm{C}}\right)$. For a gross cycle conversion efficiency of $42.5 \%, 270.588 \mathrm{MW}_{\mathrm{t}}$ of thermal power input is necessary to deliver power at the rated capacity, for which the mass flow rate of the HTF required is $635.44 \mathrm{~kg} / \mathrm{s}$. Hence, for a fixed HTF flow rate and tank height, changes in Reynolds number, $R e_{H}=\dot{m} H_{t} / \mu_{f} \pi R_{t}^{2}$, correspond to variations in the tank radius. Also, with the properties of the HTF fixed, the change in capacitance ratio and inverse Stefan number corresponds to variation in density and latent heat of fusion of the PCM, respectively.

It is understood from the SunShot vision study [28] that to achieve a levelized cost of electricity of 6 cents/kWh, equivalent to the electricity cost associated with fossil fueled power plants, improvements to all subsystems within a CSP plant is required which also includes reducing the thermal storage cost from $\$ 27 / \mathrm{kWh}_{\mathrm{t}}$ (2-tank sensible storage) to $\$ 15 / \mathrm{kWh}_{\mathrm{t}}$. The total cost of EPCM-TES storage system in units of dollar (US\$) can be expressed as the summation of storage material cost (HTF and PCM), container cost, encapsulation cost and overhead cost. The ratio of the total cost to the total storage capacity of the EPCM-TES system provides the storage cost in units of $\$ / \mathrm{kWh}_{\mathrm{t}}$. The overhead cost, accounting for the miscellaneous costs such as electrical, instrumental, piping, valves and fitting costs is assumed to be $10 \%$ of the storage material, container and encapsulation cost. The storage material cost

can be calculated as: $\left[\rho_{p}(1-\varepsilon) C_{p}^{*}+\rho_{f} \varepsilon C_{f}^{*}\right] \pi R_{t}^{2} H_{t}$ where the PCM cost per unit mass $\left(C_{p}^{*}\right)$ is assumed to be $\$ 0.75 / \mathrm{kg}$, which is the average cost of the available PCMs as tabulated in Ref. [35] and the HTF cost per unit mass $\left(C_{f}^{*}\right)$ used in the molten salt power tower CSP plant is taken 
to be $\$ 1 / \mathrm{kg}$ [36]. The EPCM-TES tank cost is calculated as explained in [36,37], which encompasses the material cost of the stainless steel (321 SS), foundation cost and the insulation cost: $\rho_{S S} H_{t}\left[\pi\left(R_{t}+w_{t}\right)^{2}-\pi R_{t}^{2}\right] \cdot C_{S S}^{*}+\pi R_{t}^{2} \cdot C_{F}^{\prime \prime}+2 \pi R_{t} H_{t} \cdot C_{I}^{\prime \prime}$, where the subscript $S S$ refers to stainless steel, the density of which is taken as $\rho_{S S}=7,900 \mathrm{~kg} / \mathrm{m}^{3}$ and $w_{\mathrm{t}}$ refers to the thickness of the tank, which is assumed to be $0.038 \mathrm{~m}$. The cost per $\mathrm{kg}$ of stainless steel $\left(C_{S S}^{*}\right)$ is obtained to be $\$ 5.43 / \mathrm{kg}$ from [38], the calcium silicate insulation cost $\left(C_{I}^{\prime \prime}\right)$ is assumed to be $\$ 235 / \mathrm{m}^{2}$ [37], and the foundation cost $\left(C_{F}^{\prime \prime}\right)$ is taken as $\$ 1,210 / \mathrm{m}^{2}[37,39]$. The cost values reported here are consistent with the values of two-tank molten salt thermal storage system reported in Ref. $[36,37]$. The cost of encapsulation is usually measured in terms of cost $/ \mathrm{kg}$ of capsule and due to lack of information about the effect of capsule radius on the encapsulation cost, it is expressed as $C_{\text {encap }}^{*}=\left(\frac{R_{c}}{0.005}\right)^{0.3} \cdot C_{\text {encap }, 0}^{*}$ where the base cost for encapsulating one $\mathrm{kg}$ of PCM in a capsule of radius $0.005 \mathrm{~m}\left(C_{\text {encap }, 0}^{*}\right)$ is assumed to be $\$ 0.75 / \mathrm{kg}$ [40]. The encapsulation cost increases with increase in capsule radius due to higher heat treatment and processing cost. Also, the stronger buoyancy driven natural convection current that will be prevalent inside the molten PCM of larger capsules during the melting process requires a thicker shell material. The total storage capacity of the EPCM-TES system can be calculated from: $\pi R_{t}^{2} H_{t}\left[\rho_{p} c_{p}(1-\varepsilon)\left(T_{C}-T_{D}\right)+\right.$ $\left.\rho_{p}(1-\varepsilon) h_{s l}+\rho_{f} c_{f} \varepsilon\left(T_{C}-T_{D}\right)\right]$. As seen from the derived expressions, the storage cost depends on the density of PCM, latent heat of fusion of PCM, capsule radius and tank radius, while the PCM melt temperature does not influence the storage cost.

The plots in Fig. 6 present the storage cost of EPCM-TES system as a function of tank radius for various parametric values considered. It is to be noted that the density and latent heat of fusion of the PCM is varied to reflect the changes in capacitance ratio and inverse Stefan number, respectively. Figure $6 \mathrm{a}-\mathrm{c}$ shows the variation in storage cost as a function of capsule radius, latent heat of fusion and density of PCM respectively for a tank height of $15 \mathrm{~m}$. In Fig. $6 \mathrm{a}$, it is observed that storage cost increases with increase in capsule radius due to increase in encapsulation cost. As tank radius increases, the storage cost decreases because of the increase in storage capacity, notwithstanding the increase in material, insulation and foundation cost. In the analysis of the effect of PCM's latent heat of fusion on the storage cost (Fig. 6b), it is found that the storage cost decreases with increase in latent heat of fusion, which is consistent with the reasoning that the storage capacity of the system increases with increase in latent energy capacity of the PCM. It is observed from Fig. 6c that the storage cost decreases with increase in density of the PCM as the storage capacity of the tank increases for a given tank dimension. It is 
to be noted that the storage cost obtained is less for a tank height of $20 \mathrm{~m}$ (not illustrated here), because of the larger storage capacity for a given HTF mass flow rate compared to a tank height of $15 \mathrm{~m}$, notwithstanding the increase in material cost.

From the plots in Fig. 6, design criteria on the EPCM-TES system parameters may be established so as to achieve a storage cost of $\$ 15 / \mathrm{kWh}_{\mathrm{t}}$ as called for in the technoeconomic target [28]. An example of this design criterion in illustrated in Figure 6a, which shows that for a tank height of $15 \mathrm{~m}$, there exists a lower bound on the tank radius, $R_{t}^{L}$, for a given capsule radius, so as to limit the storage cost to within $\$ 15 / \mathrm{kWh}_{\mathrm{t}}$. The lower bound on the tank radius increases with increase in capsule radius, as indicated by the filled markers in Fig. 6a.

Based on the variations in nondimensional charge and discharge time with different nondimensional design and operating parameters in Figs. 2-5, the system design configurations that satisfy the design targets of discharge time greater than 6 hours and charge time less than 6 hours can be identified. To illustrate this, the results obtained in Fig. 2a is presented in a dimensional form for tank heights of $15 \mathrm{~m}$ and $20 \mathrm{~m}$ in Figs. 7a-b and 7c-d, respectively. As mentioned earlier, the properties of molten salt $\left(60 \% \mathrm{NaNO}_{3}+40 \% \mathrm{KNO}_{3}\right)$ are considered to convert the nondimensional charge and discharge times defined in Eq. (3) into realistic values. A power plant of rated capacity $115 \mathrm{MW}_{\mathrm{e}}$ is considered so that the effect of Reynolds number can be captured as variation in tank radius for a given mass flow rate in a unified manner, as discussed in the beginning of Section 3.2. Figure 7a reveals an upper bound on the tank radius, $R_{t}^{U}$, for a given capsule radius so as to limit the charge time to within 6 hours while Fig. $7 \mathrm{~b}$ shows a lower bound on the tank radius, $R_{t}^{L}$, in order to achieve a discharge time greater than 6 hours. The upper bound $\left(R_{t}^{U}\right)$ and lower bound $\left(R_{t}^{L}\right)$ on the tank radius is found to increase with increase in capsule radius as presented in Figs. 7a and b. With increase in the height of the tank, as illustrated for tank height of $20 \mathrm{~m}$ in Fig. 7c and d, the upper and lower bounds on the tank radius corresponding to the constraints on charge and discharge time, respectively, are observed to decrease. Since the exergetic efficiency is greater than the target of $95 \%$, for the different design and operation parameters considered in this study (Fig. 2b), it does not pose any constraint to the selection of EPCM-TES tank radius.

Using the parametric studies shown in Figs. 2-6, Fig. 8a-f presents the design windows on the tank radius, $R_{\mathrm{t}^{\prime}}$ which identify the regions where $t_{D} \geq 6 \mathrm{~h}, t_{C} \leq 6 \mathrm{~h}, \zeta \geq 95 \%$ and $\alpha \leq$ $\$ 15 / \mathrm{kWh}_{\mathrm{t}}$ can be achieved as a function of the different design parameters of EPCM-TES system. As illustrated in Figs. 6 and 7, it is observed that the constraint on the minimum 
discharge time and the maximum storage cost forms the lower limit on the tank radius for different values of the design parameters as indicated by the solid lines and chain-dashed lines, respectively, in Fig. 8. Similarly, the dotted line is based on the maximum charge time constraint, which forms the upper bound on the tank radius in Fig. 8. The constraint on the minimum exergetic efficiency does not influence the design window since the criteria is met for all the design parameters as presented in Figs. 2-4. The shaded area identifies regions of operation, which satisfy the technical design requirements of a thermal energy storage system. The design windows illustrated in Fig. 8 are bounded by the larger of the two lower limits on the tank radius based on the discharge time and storage cost constraint and the upper limit on the tank radius based on the charge time constraint.

With increase in capsule radius, the design window shrinks to a narrow range as depicted in Fig. 8a, as the lower limit on the tank radius based on the discharge time increases. This is attributed to the increase in thermal conduction resistance for solidification with increase in capsule radius, thus requiring a larger tank radius with longer residence time of the incoming HTF. The effect of capsule radius on the increase in upper bound (charge time constraint) is not pronounced due to the fact that melting is assisted by buoyancy driven convection currents effecting efficient storage of energy. Since the storage cost increases with increase in capsule radius and tank radius (Fig. 6a), the lower bound on the tank radius based on storage cost constraint (chain-dashed line) increases with increase in capsule radius and restricts the operation of EPCM-TES system filled with large capsule radius (Fig. 8a). Figure 8b provides a comparison of the effect of capsule radius on the operation window for a tank height of $20 \mathrm{~m}$ with respect to a tank height of $15 \mathrm{~m}$ portrayed in Fig. 8a. With increase in tank height, favorable operation of the EPCM-TES system is obtained at smaller tank radius. Analyzing Fig. $8 \mathrm{a}$ and $\mathrm{b}$, it is seen that for an EPCM-TES system of height $15 \mathrm{~m}$ (Fig. 8a), the storage cost does not restrict the operation of EPCM-TES system until a capsule radius of $R_{\mathrm{c}}=28 \mathrm{~mm}$, compared to EPCM-TES height of $20 \mathrm{~m}$, where the limit on the storage cost does not favor operation of EPCM-TES system with capsule radius, $R_{c}>31 \mathrm{~mm}$ (Fig. $8 \mathrm{~b}$ ).

Within the feasible design window in Fig. 8a and $b$, the design point that gives the maximum discharge time (A) is marked by filled circle, which coincides with the minimum storage cost design point (B). The minimum charge time design point (C) is marked by filled square. In Fig. 8a and b, the maximum discharge time is obtained for higher tank radius and lower capsule radius while the minimum charge time is obtained for lower tank and capsule 
radii. The maximum discharge time, as marked by filled circles, is higher for tank height of $15 \mathrm{~m}$ $\left(t_{\mathrm{D}}=7.01 \mathrm{~h}\right)$ compared to a tank radius of $20 \mathrm{~m}\left(t_{\mathrm{D}}=6.99 \mathrm{~h}\right)$. Since the charge and discharge time decreases with increase (decrease) in Reynolds number (tank radius) as depicted in Fig. 2a (Fig. $7 \mathrm{a}-\mathrm{b})$, the maximum discharge time obtained for $H_{\mathrm{t}}=20 \mathrm{~m}$ is lesser than that obtained for $H_{\mathrm{t}}=$ $15 \mathrm{~m}$. Likewise the minimum charge time (square markers) and storage cost (circle markers) for $H_{\mathrm{t}}=15 \mathrm{~m}$, are obtained to be $5.14 \mathrm{~h}$ and $\$ 11.64 / \mathrm{kWh}_{\mathrm{t}^{\prime}}$ respectively, which are less than the corresponding values obtained for $H_{\mathrm{t}}=20 \mathrm{~m}$ namely, $t_{\mathrm{D}}=5.15 \mathrm{~h}$ and $\alpha=\$ 11.98 / \mathrm{kWh}_{\mathrm{t}}$.

Figure 8c illustrating the effect of latent heat of fusion of PCM on the design window shows that upper bound on $R_{t}$ dictated by the charge time constraint decreases slightly while the lower bound on $R_{t}$ decided by the discharge time constraint decreases initially and then settles to a constant value. With increase in latent heat of fusion and thermal inertia of the system, a smaller tank radius with faster HTF flow velocity and correspondingly higher heat transfer coefficient is required for efficient heat exchange between the HTF and PCM. While the increase in thermal inertia affects the conduction dominated solidification rate, its influence on the natural convection assisted melting rate is not compelling, which results in an inconsequential effect on the upper bound set by the charge time constraint. The range of tank radius that provides feasible operation of the storage system is broader for higher $h_{\mathrm{sl}}$. It should be noted that for an $h_{\mathrm{sl}}$ $<162.8 \mathrm{~kJ} / \mathrm{kg}$, the constraint on the storage cost restricts the storage system operation (Fig. 8c) due to the decrease in storage capacity of the EPCM-TES system.

From Fig. 8d, it is observed that as density of PCM increases the upper bound and lower bound on the tank radius decreases. As PCM density increases, the storage capacity of the EPCM-TES system also increases, which leads to an increase in charge and discharge time for a given tank radius. Due to the inverse (direct) dependence of charge and discharge time with Reynolds number (tank radius), as depicted in Fig. 2c, the EPCM-TES system filled with capsules containing low PCM density has feasible design windows for larger tank radius and vice-versa. Due to the increase in storage cost with increase in PCM density as revealed in Fig. $6 c$, it is observed that the design window of EPCM-TES system narrows for density of PCM less than $1,135 \mathrm{~kg} / \mathrm{m}^{3}$. The maximum discharge time and minimum storage cost are obtained for higher PCM density (circle marker) while the minimum charge time is obtained for lower PCM density (square marker).

The effects of other parameters of non-cascaded EPCM-TES system on the design window, though not illustrated here, may be summarized as follows: A very narrow design window is 
observed for PCM with melt temperatures in the range $T_{D}^{\prime} \leq T_{m}<T_{C}$ and PCM melt temperature below $T_{D}^{\prime}$ does not have a feasible design window. This is attributed to the fact that PCM with melt temperature below $T_{D}^{\prime}$ requires a higher charge time to attain the corresponding discharge time (Fig. 3a and b).

Figure 8e illustrates the effect of varying PCM melt temperature at the bottom zone of a 2PCM cascaded EPCM-TES system on the operation window. For PCM with melt temperature less than $352.5 \mathrm{C}\left(\theta_{m}=0.22\right)$ and greater than $403.6 \mathrm{C}\left(\theta_{m}=0.4\right)$, feasible design window is observed as portrayed in Fig. 8e. As PCM melt temperature in the bottom zone increases from $T_{D^{\prime}}$ the tank radius which satisfies the charge (dotted line) and discharge (solid line) time requirements also decreases reflecting the fact that higher charge and discharge time is achieved with increase in PCM melt temperature (Fig. 4b). Even though the discharge and charge time follows the same trend with variations in PCM melt temperature as portrayed in Fig. 4b, beyond $T_{m}=352.5 C\left(\theta_{m}=0.22\right)$, smaller Reynolds number or larger tank radius is required to satisfy the constraint on the discharge time compared to the tank radius required to satisfy the constraint on the charge time, thus leading to infeasible operation of EPCM-TES system between PCM melt temperatures of 0.22 and 0.40 in the bottom zone. At higher PCM melt temperatures, $T_{m}\left(\theta_{m}\right)>403.6 C(0.40)$, for a given Reynolds number, the discharge time is higher compared to the charge time because none of the zones contain PCM within the temperature range of $T_{\mathrm{D}}$ and $T_{C}^{\prime}$ to prolong the charging operation of EPCM-TES system. Hence, the tank radius satisfying the discharge time constraint is smaller compared to the tank radius that satisfies the charge time constraint and a feasible design window is observed in Fig. 8e. The effect of top zone height of a 2-PCM cascaded configuration on the operation window (not illustrated here) showed that the feasible design window is observed for larger top zone heights, since a higher percentage of the storage system is packed with PCM of higher melt temperature. A feasible operation window as a function of top zone PCM melt temperature is not obtained because the charge time is found to be greater than the discharge time for the entire range of PCM melt temperature, as portrayed in Fig. 4a.

Figure 8f portrays the effect of simultaneously varying the bottom and top zone heights on the design window. Feasible design window is obtained for small bottom zone height, $\left(H_{3, B}^{\prime}\right)$ and large top zone height, $H_{3, T}^{\prime}$, when the bulk of the storage system is filled with PCM of higher melt temperature. The design window shown in Fig. 8f is obtained for bottom zone height corresponding to which, the discharge time is greater than the charge time as illustrated 
in Fig. 5f. Similar operation window as a function of other zone heights and PCM melt temperatures can be obtained, but is not illustrated here in the interest of brevity.

From the design windows on tank radius obtained for the various design parameters, the design configurations that maximizes the discharge time, and minimizes the charge time, storage capital cost are obtained. Table 3 lists the combinations of parameters culled from the parametric studies that: (1) maximizes discharge time, $t_{\mathrm{D}^{\prime}}(2)$ maximizes charge time, $t_{\mathrm{C}^{\prime}}$ and (3) minimizes storage cost, $\alpha$ within the design window of EPCM-TES operation for non-cascaded, 2-PCM cascaded and 3-PCM cascaded configurations. The maximum or minimum values of the objective function are listed in bold face and the corresponding design configuration is highlighted in Table 3.

It is seen from Table 3a that of the cases studied, the best combination of parameters that maximizes $t_{\mathrm{D}}$ for non-cascaded EPCM-TES system yields discharge time of $7.42 \mathrm{~h}$ for $H_{\mathrm{t}}=15 \mathrm{~m}$ (Table 3a.1). It was observed that the tank radius, $R_{\mathrm{t}}$ corresponding to the best configuration decreases with increase in EPCM-TES height, which leads to a lower discharge time for $H_{t}=20$ $\mathrm{m}$ and is not listed here. Also, it is observed that the maximum discharge time corresponds to case with higher latent heat of fusion with the rest of the parameters at the default values, which is represented by the filled circles (design point A) in Fig. 8c. For a 2-PCM cascaded configuration, the maximum discharge time of $6.91 \mathrm{~h}$ is obtained for EPCM-TES system with top zone height of $15 \mathrm{~m}$. Another important observation is that the charge time of the EPCMTES system corresponding to maximum $t_{\mathrm{D}}$ corresponds to 6 hours for all the EPCM-TES system configurations namely non-cascaded, 2-PCM and 3-PCM cascaded EPCM-TES system, which sets the upper bound on the tank radius for various design parameters as presented in Fig. 8. Table $3 \mathrm{~b}$ presents the configurations of the storage system, which provided the minimum charge time and the optimum system configuration are the same as those obtained for maximum discharge time presented in Table 3a. However, the minimum charge time, for a given tank height is obtained for smaller tank radius values corresponding to which the discharge time is 6 hours. Among all the configurations, the minimum charge time of $t_{\mathrm{C}}=4.86 \mathrm{~h}$ is obtained for non-cascaded configuration (Table 3b.1). The design point corresponding to the minimum charge time of the non-cascaded configuration is represented by the filled squares (design point C) in Fig. 8c. The minimum storage cost for the different configurations of storage system reported in Table 3c corresponds to system with highest latent heat of fusion and hence higher energy storage capacity. The minimum storage cost also corresponds to the upper bound 
of the design window based on the charge time constraint (Fig. 8) with larger tank radius and higher volumetric storage capacity. Among the parametric studies considered in this study, the non-cascaded configuration has the minimum storage cost, $\alpha=\$ 7.55 / \mathrm{kWh}_{\mathrm{t}}$ in Table $3 \mathrm{c} .1$, since the energy storage capacity is at least 50\% higher compared to a 2-PCM cascaded configuration (Table 3c.2) and at least 66.7\% higher compared to a 3-PCM cascaded configuration (Table 3c.3).

\section{Numerical Optimization}

The best configurations obtained from the parametric studies (Figs. 2-7) and the design windows (Fig. 8) reported in Table 3 are obtained from varying one parameter at a time with the rest of the parameters at the design values. It is imperative that an optimization procedure varying all the design parameters simultaneously is conducted to find the optimum combination of design and operating parameters while also achieving the technoeconomic targets.

The goal of the optimization is to determine the design parameters of the EPCM-TES system so as to minimize the storage cost. The optimization is subject to operation constraints on the charge time, discharge time and exergetic efficiency defined previously. The decision variables whose optimum values are sought to be determined ranges from 5 variables for a non-cascaded system configuration to 14 variables for a 3-PCM cascaded system configuration. For a 3-PCM cascaded storage system the decision variable are the density, latent heat of fusion, melt temperature of the PCM in each of the three zones, the height ratio of each of the zones, the tank radius and the capsule radius. In this optimization study as explained in Section 3.2, a $115 \mathrm{MW}_{\mathrm{e}}$ CSP plant is considered for which the desired flow rate of the HTF $(635.44 \mathrm{~kg} / \mathrm{s})$ is fixed and the optimum Reynolds number pertains to the desired tank radius which minimizes the storage cost and hence is also considered to be a decision variable. The upper and lower bounds of the decision variables considered for the study are listed in Table 4 and the optimization problem can be written mathematically as:

$$
\underset{\rho_{p}, T_{m}, h_{s l}, H^{\prime}, R_{c}, R_{t}}{\operatorname{Minimize}} \alpha
$$

subject to

$$
\begin{aligned}
& g_{1}=t_{C}-t_{c r i t} \leq 0 \\
& g_{2}=t_{D}-t_{c r i t} \geq 0 \\
& g_{3}=\zeta-\zeta_{c r i t} \geq 0
\end{aligned}
$$


The physical significance of the constraints are as follows: The storage system for a CSP plant should be charged in 6 hour period $\left(t_{\text {crit }}\right)$ which is the equivalent of excess energy available from solar irradiation during the day for a $115 \mathrm{MW}_{\mathrm{e}}$ power plant. Similarly, the storage system should assist in the generation of electricity for more than $6 \mathrm{~h}$ during the nighttime when solar energy is unavailable. The exergy efficiency takes care of the amount of useful thermal energy charged that can be converted into electricity and should be greater than 95\% [1]. Since for the various parameters considered, the exergetic efficiency is greater than $95 \%$ (Figs. 2, 3) the constraint is imposed on the overall exergetic efficiency. Moreover, the upper limits of the density and latent heat of fusion considered in Table 4 are within the realistic properties of available PCM. For instance, inorganic salt compositions such as $20 \% \mathrm{LiF}+80 \% \mathrm{LiOH}$ and $46 \%$ $\mathrm{LiF}+44 \% \mathrm{NaF}_{2}+10 \% \mathrm{MgF}_{2}$ have latent heat of fusion values of $869 \mathrm{~kJ} / \mathrm{kg}$ and $858 \mathrm{~kJ} / \mathrm{kg}$, respectively. Some of the PCMs with high densities are $45 \% \mathrm{NaBr}+55 \% \mathrm{MgBr}_{2}\left(\rho_{p}=\right.$ $\left.3490 \mathrm{~kg} / \mathrm{m}^{3}\right)$ and $\mathrm{CaI}_{2}\left(\rho_{p}=3956 \mathrm{~kg} / \mathrm{m}^{3}\right)$.

The optimization problem represented by Eqs. (8a) and (8b) is solved using the NelderMead simplex method [41] combined with a simulated annealing technique to improve the effectiveness of the search $[42,43]$. The simplex search method is an algorithm that performs continuous search for selecting a new point during an optimization iteration, which guarantees objective function improvement. A simplex is defined as a convex hull of $N+1$ vertices in an $N$ dimensional space, representing the $N$ decision variables that govern the objective function evaluation. The vertices are ranked, from best to worst, based on the corresponding objective function evaluations and the best vertex is defined as the primary vertex. Since the primary vertex corresponds to a set of decision variables, which corresponds to the lowest objective function evaluation, the finding of a new primary vertex constitutes an improvement to the objective function. The Nelder-Mead simplex method combined with simulated annealing is designed to solve non-linear unconstrained problems. Since the optimization problem in hand has several constraints, $g_{k^{\prime}}$ those constraints are incorporated using a penalty method [44] into an augmented objective function to be minimized, such that the optimization problem now becomes unconstrained:

$$
\underset{\rho_{p}, T_{m}, h_{s l}, H^{\prime}, R_{c}, R_{t}}{\operatorname{Minimize}} \alpha+\sum_{k} p_{k} \max \left(g_{k}, 0\right)
$$


where $p_{\mathrm{k}}$ are the penalty factors. The main drawback of penalty functions is that the penalty factors require a careful fine tuning, which determines the severity of penalization to be applied in order to obtain the optimum solution within the feasible region. Although increasing the penalty parameters improves the solution accuracy, the unconstrained formulation can also become very ill-conditioned with large gradients and abrupt function changes. For the present problem, a value of $p_{\mathrm{k}}=1000$ was found to strictly enforce the constraints, without making the optimization problem formulation ill-conditioned.

For instance, the 14 decision variables in a 3-PCM cascaded EPCM-TES system configuration leads to a simplex formed by fourteen-dimensional space and consists of fifteen vertices. Initial guess for the decision variables correspond to one of the vertices, and adding scaled basis unit vectors creates the other fifteen vertices, such that the hyper-surfaces are independent of each other. The numerical model (Section 2.2) and the cost model (Section 3.2) are then invoked to determine the objective function and constraints respectively, corresponding to each vertex at every step of the optimization procedure. Upon completion of the optimization algorithm, the decision variables corresponding to the primary vertex are the optimal decision variable vector and the corresponding objective function value taken as the optimal storage cost, $\alpha$.

Table 5 lists the designs corresponding to the optimization problems formulated by Eqs. (8a) and (8b). The storage cost obtained for a non-cascaded configuration from the numerical optimization are much lower than those obtained from the parametric studies, cf. $\alpha=$ $\$ 5.79 / k W h_{t}$ (Table 5a), and $\alpha=\$ 7.55 / \mathrm{kWh}_{\mathrm{t}}$ (Table 3c.1) for tank height of $15 \mathrm{~m}$. Similarly, the storage costs obtained for a 2-PCM cascaded EPCM-TES system configuration $\alpha=\$ 5.74 / \mathrm{kWh}_{\mathrm{t}}$ (Table 5b) is much lower compared to that obtained from parametric studies, $\alpha=\$ 10.13 / \mathrm{kWh}_{\mathrm{t}}$ (Table 3c.2) for tank height of $15 \mathrm{~m}$. On further observation, the optimum values for a $2 \mathrm{PCM}$ cascaded configuration are obtained for a configuration with the maximum storage capacity, i.e with the highest PCM density and latent heat of fusion (Table 5b). The optimum design parameters obtained for all the non-cascaded and cascaded configurations in Table 5 show that smallest capsule radius of $R_{c}=3.75 \mathrm{~mm}$ is preferred due to the low encapsulation cost. The storage cost for a 3-PCM cascaded configuration obtained from the optimization studies is relatively higher compared to a 2-PCM cascaded configuration (Table $5 b$ and $5 c$ ). However, an optimum 3-PCM cascaded configuration gives the highest discharge time among all the cases, cf. $t_{\mathrm{D}}=6.62 \mathrm{~h}$ for tank height of $15 \mathrm{~m}$. Compared to the result of the parametric studies, the 
storage cost obtained for a 3-PCM cascaded configuration from the optimization study is approximately two times lower. The optimization results for 2-PCM and 3-PCM cascaded configuration in Table $5 \mathrm{~b}$ and Table 5c, respectively, also show that a larger percentage of the tank should be filled with PCM's with melt temperature in the range $T_{D}^{\prime} \leq T_{m} \leq T_{C}$, to satisfy the constraint on exergetic efficiency. From the optimization study it can be concluded that a 2PCM cascaded configuration offers the lowest storage cost and 3-PCM cascaded configuration offers the highest discharge and lowest charge times. Further improvement in cascading will lead to only minor improvement as seen from the negligible difference in results between 2PCM and 3-PCM cascaded configurations.

The present study involves a detailed investigation of the EPCM-TES system performance to obtain the optimum design and operating parameters of non-cascaded and cascaded configurations that meet the technoeconomic requirements for cost parity of solar-generated electricity. The authors have also investigated the EPCM-TES system performance integrated with CSP plant performance model to obtain design and operation windows which result in a levelized cost of electricity less than 6 cents $/ \mathrm{kWh}$, to be on par with the electricity cost associated with fossil fueled power plants [45]. Based on the findings of Ref. [46], future studies will involve coupling the numerical model for EPCM-TES system with an optimization scheme to determine the optimum cascaded EPCM-TES system configuration for realistic weather conditions.

\section{Conclusions}

An EPCM-TES model accounting for axial variation of temperature in the HTF and radial temperature variation in the PCM at any axial position is solved and the effects of various nondimensional design and operating parameters on the dynamic performance of the storage system are analyzed. Important results pertaining to the analysis above can be summarized as follows: Smaller radii capsules yield higher discharge and charge time of the EPCM-TES system, higher Reynolds number and consequently higher mass flow rate leads to decrease in discharge and charge time, higher inverse Stefan number and capacitance ratio correspond to an EPCM-TES system with higher thermal inertia resulting in an increased charge and discharge time. For all the various parameters and EPCM-TES system configurations (noncascaded, 2-PCM cascaded and 3-PCM cascaded) the exergetic efficiency at the periodic quasisteady state was found to be greater than $95 \%$. 
Based on a systematic parametric analysis on the various performance metrics, feasible operating regimes and design conditions are identified which meet the technoeconomic requirements: (a) charge time less than 6 hours, (b) discharge time greater than 6 hours, (c) exergetic efficiency greater than $95 \%$ and (d) storage cost less than $\$ 15 / \mathrm{kWh}_{\mathrm{t}}$. The best combination of parameters that maximized the various performance metrics are tabulated in Table 3. The maximum discharge time of $7.42 \mathrm{~h}$ and a minimum storage cost of $\$ 7.55 / \mathrm{kWh}_{\mathrm{t}}$ are obtained for a non-cascaded EPCM-TES tank of height, $15 \mathrm{~m}$ and radius, $11.25 \mathrm{~m}$, filled with 15 mm radius capsules containing PCM of density, $1975.5 \mathrm{~kg} / \mathrm{m}^{3}$ and latent heat of fusion, 852 $\mathrm{kJ} / \mathrm{kg}$. Since the parametric studies allowed for analyzing the performance of EPCM-TES by varying only one parameter at a time, the effect of varying all the parameters simultaneously is studied by means of an optimization procedure. The optimum combination of parameters that minimized the storage cost is presented in Table 5. The minimum storage cost of $\$ 5.539 / \mathrm{kWht}$ is obtained for a 2-PCM cascaded EPCM-TES tank of height $15 \mathrm{~m}$ and radius $9.31 \mathrm{~m}$ and filled with capsules of radius $3.75 \mathrm{~mm}$. Overall, this paper presents a methodology for model based design and optimization of the EPCM-TES system based on the systematic parametric studies and consideration of target design requirements on the dynamic operation of the system.

\section{Acknowledgements}

This work was supported by a grant from the U.S. Department of Energy SunShot Initiative under Award Number DE-FG36-08GO18146. Their support is gratefully acknowledged.

\section{Nomenclature}

$\begin{array}{ll}b & \text { capsule wall thickness }[\mathrm{m}] \\ b^{*} & \text { dimensionless capsule wall thickness } \\ c & \text { specific heat }[\mathrm{J} / \mathrm{kg}-\mathrm{K}] \\ C^{*} & \text { cost per unit mass }[\$ / \mathrm{kg}] \\ C^{\prime} & \text { cost per unit length }[\$ / \mathrm{m}] \\ C^{\prime \prime} & \text { cost per unit area }\left[\$ / \mathrm{m}^{2}\right] \\ f_{L} & \text { liquid fraction } \\ h & \text { convective heat transfer coefficient }\left[\mathrm{W} / \mathrm{m}^{2}-\mathrm{K}\right] \\ h_{s l} & \text { latent heat of fusion of } \mathrm{PCM}[\mathrm{J} / \mathrm{kg}] \\ H & \text { height }[\mathrm{m}]\end{array}$




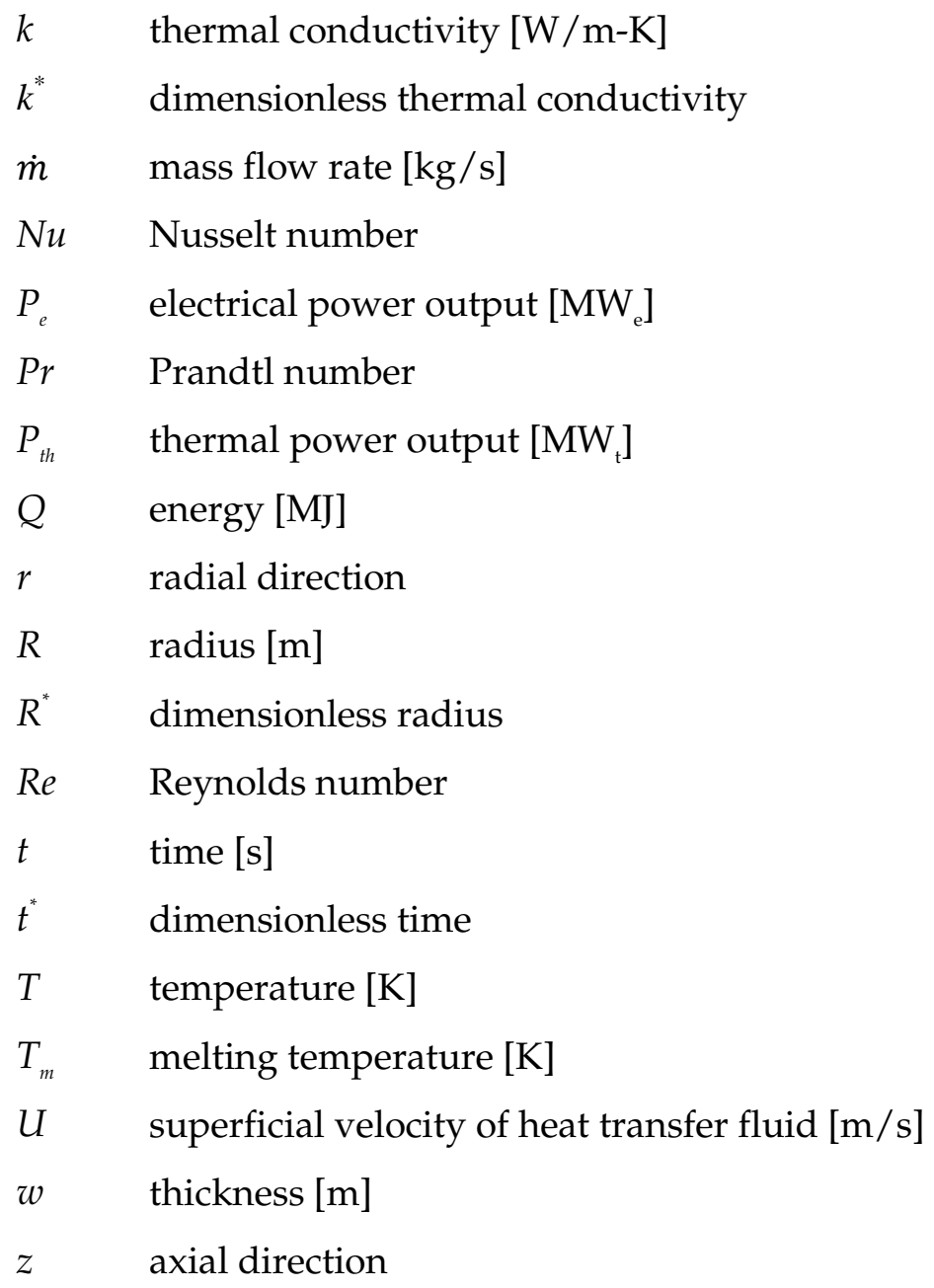




$\begin{array}{ll}L & \text { latent } \\ M & \text { middle } \\ p & \text { phase change material } \\ S S & \text { stainless steel } \\ t & \text { tank } \\ T & \text { top } \\ \text { eff } & \text { effective }\end{array}$

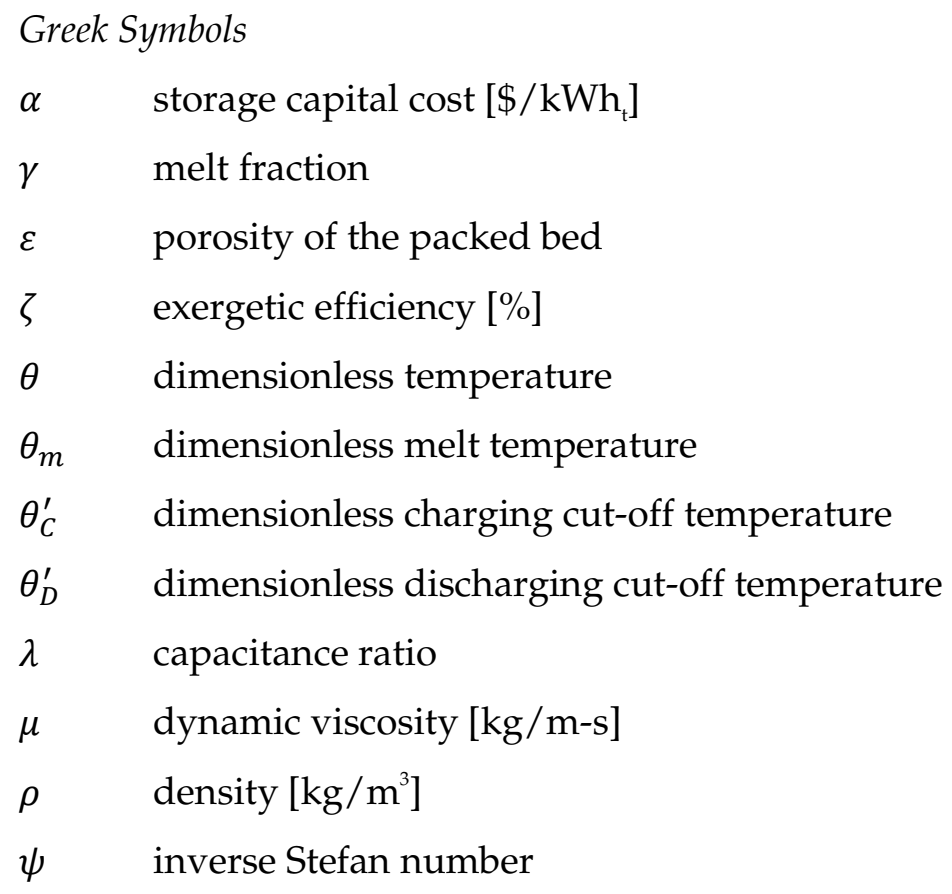

\section{References}

[1] Stekli, J., Irwin, L., Pitchumani, R., 2013. Technical challenges and opportunities for concentrating solar power with energy storage. ASME Journal of Thermal Science Engineering and Applications. 5, 021011-1-12.

[2] Nithyanandam, K., Pitchumani, R., 2011. Analysis and optimization of a latent thermal energy storage system with embedded heat pipes. Int. J. Heat and Mass Transfer. 54, 4596-4610.

[3] Nithyanandam, K., Pitchumani, R., 2013. Computational studies on a latent thermal energy storage system with integral heat pipes for concentrating solar power. Applied Energy. 103, 400-415. 
[4] Nithyanandam, K., Pitchumani, R., 2014. Computational modeling of dynamic performance of a latent thermal energy storage system with embedded heat pipes. ASME J. Sol. Engineering. 136, 011010-1-9.

[5] Nithyanandam, K., Pitchumani, R., 2013. Thermal energy storage with heat transfer augmentation using thermosyphons. Int. J. Heat and Mass Transfer. 67, 281-294.

[6] Mettawee, E. S., Assassa, G. M. R., 2007. Thermal conductivity enhancement in a latent heat storage system. Solar Energy. 81, 839-845.

[7] Nithyanandam, K., Pitchumani R., 2014. Computational studies on metal foam and heat pipe enhanced latent thermal energy storage. ASME J. Heat Transfer. 136, 051503-1-10.

[8] Zhao, Z. Y., Wu, Z. G., 2011. Heat transfer enhancement of high temperature thermal energy storage using metal foams and expanded graphite. Solar Energy Materials and Solar Cells. 95, 636-643.

[9] Cárdenas, B., León, N., 2013. High temperature latent heat thermal energy storage: Phase change materials, design considerations and performance enhancement techniques. Renewable and Sustainable Energy Reviews. 27, 724-737.

[10] Nithyanandam, K., Pitchumani, R., 2014. Analysis of a latent thermocline storage system with encapsulated phase change materials for concentrating solar power. Applied Energy. 113, 1446-1460.

[11] Mathur, A., Kasetty, R., Oxley, J., Mendez, J., Nithyanandam, K., 2013. Using encapsulated phase change salts for concentrated solar power plant, Energy Procedia, Proceedings of SolarPACES 2013, Las Vegas, Nevada, R. Pitchumani, ed. 7pp.

[12] Pendyala, S., 2012. Macroencapsulation of phase change materials for thermal energy storage. M.S Thesis, University of South Florida.

[13] Schumann, T. E. W., 1929. Heat transfer: A liquid flowing through a porous prism. J. Franklin Inst. 208, 405-416.

[14] Shitzer, A., Levy, M., 1983. Transient behavior of a rock-bed thermal storage system subjected to variable inlet air temperature: Analysis and Experimentation. ASME J. Sol. Energy Eng. 105, 200-206.

[15] Yang, Z., Garimella, S. V., 2010. Thermal analysis of solar thermal energy storage in a molten-salt thermocline. Solar Energy. 84, 974-985.

[16] Beasley, D. E., Clark, J. A., 1984. Transient response of a packed bed for thermal energy storage. Int. J. Heat and Mass Transfer. 27, 1659-1669. 
[17] Yang, Z., Garimella, S. V., 2010. Molten-salt thermal energy storage in thermoclines under different environmental boundary conditions. Applied Energy. 87, 3322-3329.

[18] Van Lew, J. T., Li, P., Chan, C. L., Karaki, W., Stephens, J., 2011. Analysis of heat storage and delivery of a thermocline tank having solid filler material. J. Sol. Energy Engineering. 133, 021003-1-10.

[19] Yang, Z., Garimella, S. V., 2013. Cyclic operation of molten-salt thermal energy storage in thermoclines for solar power plants. App. Energy. 103, 256-265.

[20] Wakao, N., Kagei, S., 1982. Heat and mass transfer in packed beds. Gordon and Breach Science, New York.

[21] Ismail, K. A. R., Henriquez, J. R., 1999. Numerical and experimental study of spherical capsules packed bed latent heat storage system, App. Thermal Eng. 19, pp. 757-788.

[22] Felix Regin, A., Solanki, S. C., Saini, J. S., 2008. Heat transfer characteristics of thermal energy storage system using PCM capsule: a review. Renew and Sus. Ener. Reviews. 12, $2438-2458$.

[23] Singh, H., Saini, R .P, Saini, J. S., 2011. A review on packed bed solar energy storage system. Renew and Sus. Ener. Reviews. 14, 1059-1069.

[24] Felix Regin, A., Solanki, S. C., Saini, J. S., 2009. An analysis of a packed bed latent heat thermal energy storage system using PCM capsules: Numerical investigation. Renew. Ener. 34, 1765-1773.

[25] Wu, S., Fang, G., 2011. Dynamic performance of solar heat storage system with packed bed using myristic acid as phase change material. Energy and Buildings. 43, 1091-1096.

[26] Wang, J., Chen, G., Jiang, H., 1999. Theoretical study on a novel phase change process. Int. J. Energy Res. 23, 287-294.

[27] Gong, Z.X., Mujumdar, A.S., 1997. Thermodynamic optimization of the thermal process in energy storage using multiple phase change materials. Appl. Therm. Eng. 17, 10671083.

[28] SunShot, Energy Efficiency and Renewable Energy, U.S. Department of Energy, 2012. SunShot Vision Study: February 2012. NREL Report No. BK5200-47927; DOE/GO102012-3037, http:/ / www.solar.energy.gov/pdfs/47927.pdf (Accessed: February 2013).

[29] Hales, T.C., 2006. Historical overview of the Kepler conjecture, Discrete \& Computational Geometry. International Journal of Mathematics and Computer Science. 36, 5-20.

[30] Galloway, T. R., Sage, B. H., 1970. A model of the mechanism of transport in packed, 
distended, and fluidized beds, Chemical Engg. Sci. 25, 495-516.

[31] Voller, V.R., Cross, M., Markatos, N.C., 1987. An enthalpy method for convection/diffusion phase change. Int. J. Numer. Methods. 24, 271-284.

[32] Patankar, S. V., 1980. Numerical heat transfer and fluid flow. Hemisphere, Washington, D. C.

[33] System Advisor Model Version 2012.5.11 (SAM 2012.5.11), User Documentation. National Renewable Energy Laboratory, Golden, CO.

[34] Flueckiger, S., Yang, Z., Garimella S. V., 2013. Review of molten salt thermocline tank modeling for solar thermal energy storage. Heat Transfer Engg. 34, 787-800.

[35] Kenisarin, M. M., 2010. High-temperature phase change materials for thermal energy storage. Renew and Sus. Ener. Reviews. 14, 955-970.

[36] Glatzmaier, G., 2011. Developing a cost model and methodology to estimate capital costs for thermal energy storage. National Renewable Energy Laboratory, NREL/TP550053066, 1-17.

[37] Kelly, B., Kearney, D., 2006. Thermal storage commercial plant design for a 2-tank indirect molten salt system. National Renewable Energy Laboratory, NREL/SR$550040166,1-32$.

[38] MEPS International Ltd., <www.meps.co.uk>, viewed: November-December 2012.

[39] Herrmann, U., Kelly, B., Price, H., 2004. Two-tank molten salt storage for parabolic trough solar power plants. Energy. 29, 883-893.

[40] Mathur, A., 2012, Personal Communication, Terrafore, Inc.

[41] Nelder, J. A., Mead, R., 1965. A simplex method for function minimization. Comput. J. (UK). 7, $308-313$.

[42] Mawardi, A., Pitchumani, R., 2003. Optimal temperature and current cycles for curing of composites using internal resistive heating. ASME J. Heat Trans. 125, 126-136.

[43] Press, W. H., Flannery, B. P., Teukolsky, S. A., Vettering, W. T., 1992. Numerical Recipes in FORTRAN. Cambridge University Press, New York, NY.

[44] Bertsekas, D. P., 1999. Nonlinear Programming. Athena Scientific, Belmont, MA.

[45] Nithyanandam, K., Pitchumani, R., 2014. Cost and performance analysis of concentrating solar power systems with integrated latent thermal energy storage. Energy, 64, 793-810.

[46] Muren, R., Arias, D., Chapman, D., Erickson, L., Gavilan, A., 2011. Coupled transient system analysis: A new method of passive thermal energy storage modeling for high 
temperature concentrated solar power systems. Proceedings of the ASME 5th International Conference on Energy Sustainability, Paper No. ES2011-54111, Washington, DC, USA. 
Table 1: Dimensionless design and operating parameters investigated ( N-C: non cascaded; 2-C: 2-PCM cascaded; 3-C: 3-PCM cascaded)

\begin{tabular}{cccc}
\hline \hline System Configuration & Parameters & Design Intervals & Default Value \\
\hline$N-C, 2-C, 3-C$ & Capsule radius, $R_{C}^{*}$ & $0.00025 \leq R_{C}^{*} \leq 0.0025$ & 0.001 \\
$N-C, 2-C, 3-C$ & Capacitance ratio, $\lambda$ & $0.5 \leq \lambda \leq 1.5$ & 1 \\
$N-C, 2-C, 3-C$ & Stefan number, $\psi$ & $0.0 \leq \psi \leq 2.0$ & 0.5 \\
$N-C, 2-C, 3-C$ & Reynolds number, $R_{H}$ & $10000 \leq R e_{H} \leq 25000$ & 25000 \\
$N-C$ & PCM Melt Temperature, $\theta_{m}$ & $0.00 \leq \theta_{m} \leq 1.00$ & 0.75 \\
$2-C$ & Bottom zone PCM melt temperature, $\theta_{m, B}$ & $0.00 \leq \theta_{m, B} \leq 0.75$ & 0.25 \\
$2-C$ & Top zone PCM melt temperature, $\theta_{m, T}$ & $0.25 \leq \theta_{m, T} \leq 1.00$ & 0.75 \\
$3-C$ & Bottom zone PCM melt temperature, $\theta_{m, B}$ & $0.00 \leq \theta_{m, B} \leq 0.50$ & 0.25 \\
$3-C$ & Middle zone PCM melt temperature, $\theta_{m, M}$ & $0.25 \leq \theta_{m, M} \leq 0.75$ & 0.50 \\
$3-C$ & Top zone PCM melt temperature, $\theta_{m, T}$ & $0.50 \leq \theta_{m, T} \leq 1.00$ & 0.75 \\
\hline \hline
\end{tabular}


Table 2: Cyclic results obtained for default 3-PCM cascaded configuration (The value in brackets shows the variation in results between the current and the preceding cycle)

\begin{tabular}{ccccccc}
\hline \hline Cycle & \multicolumn{2}{c}{ Charge Time, $t_{C}^{*}\left[\times 10^{-5}\right]$} & \multicolumn{2}{c}{ Discharge Time, $t_{D}^{*}\left[\times 10^{-5}\right]$} & \multicolumn{2}{c}{ Exergetic Efficiency, $\zeta[\%]$} \\
\hline 1 & 1.205 & & 1.119 & & 90.21449 & \\
2 & 1.128 & $(6.83 \%)$ & 1.112 & $(0.63 \%)$ & 96.80934 & $(6.81 \%)$ \\
3 & 1.126 & $(0.18 \%)$ & 1.111 & $(0.09 \%)$ & 96.99082 & $(0.19 \%)$ \\
4 & 1.126 & $(0.00 \%)$ & 1.111 & $(0.00 \%)$ & 97.01631 & $(0.03 \%)$ \\
5 & 1.126 & $(0.00 \%)$ & 1.111 & $(0.00 \%)$ & 97.01502 & $\left(1.33 \times 10^{-3} \%\right)$ \\
6 & 1.126 & $(0.00 \%)$ & 1.111 & $(0.00 \%)$ & 97.01433 & $\left(7.11 \times 10^{-4} \%\right)$ \\
7 & 1.126 & $(0.00 \%)$ & 1.111 & $(0.00 \%)$ & 97.01403 & $\left(3.09 \times 10^{-4} \%\right)$ \\
8 & 1.126 & $(0.00 \%)$ & 1.111 & $(0.00 \%)$ & 97.01390 & $\left(1.34 \times 10^{-4} \%\right)$ \\
9 & 1.126 & $(0.00 \%)$ & 1.111 & $(0.00 \%)$ & 97.01385 & $\left(5.15 \times 10^{-5} \%\right)$ \\
10 & 1.126 & $(0.00 \%)$ & 1.111 & $(0.00 \%)$ & 97.01383 & $\left(2.06 \times 10^{-5} \%\right)$ \\
11 & 1.126 & $(0.00 \%)$ & 1.111 & $(0.00 \%)$ & 97.01382 & $\left(1.03 \times 10^{-5} \%\right)$ \\
12 & 1.126 & $(0.00 \%)$ & 1.111 & $(0.00 \%)$ & 97.01381 & $\left(1.03 \times 10^{-5} \%\right)$ \\
13 & 1.126 & $(0.00 \%)$ & 1.111 & $(0.00 \%)$ & 97.01381 & $(0.00 \%)$ \\
14 & 1.126 & $(0.00 \%)$ & 1.111 & $(0.00 \%)$ & 97.01381 & $(0.00 \%)$ \\
15 & 1.126 & $(0.00 \%)$ & 1.111 & $(0.00 \%)$ & 97.01381 & $(0.00 \%)$ \\
\hline
\end{tabular}




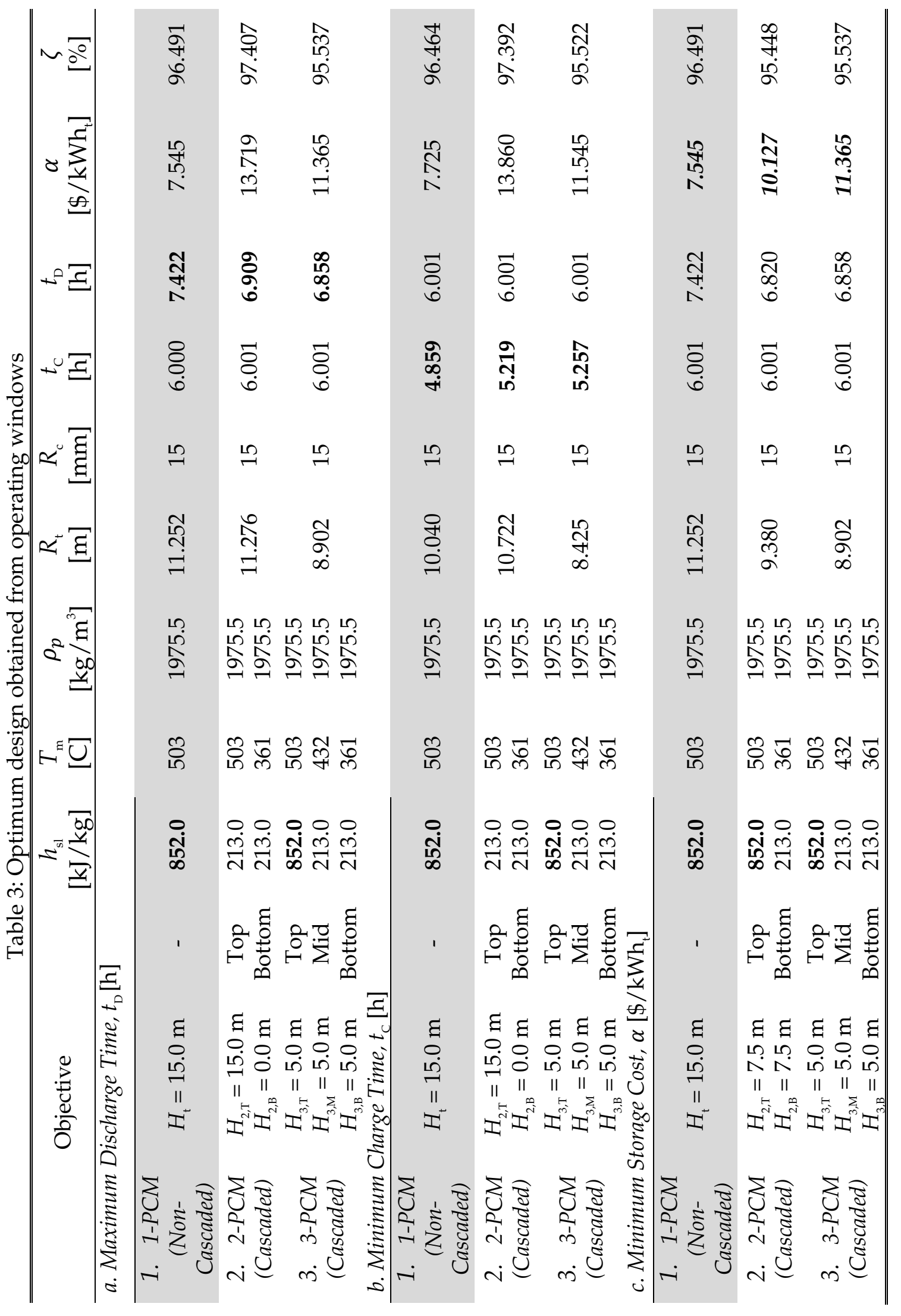


Table 4: Design parameters considered in the study

\begin{tabular}{cccc}
\hline \hline Parameters & Symbol & Units & Design Intervals \\
\hline Tank Radius & $R_{\mathrm{t}}$ & $\mathrm{m}$ & $7.5 \leq R_{t} \leq 12.5$ \\
Capsule Radius & $R_{\mathrm{c}}$ & $\mathrm{mm}$ & $3.75 \leq R_{c} \leq 37.5$ \\
PCM Density & $\rho_{\mathrm{p}}$ & $\mathrm{kg} / \mathrm{m}^{3}$ & $987.75 \leq \rho_{p} \leq 3951.00$ \\
PCM Melt Temperature & $T_{\mathrm{m}}$ & $\mathrm{C}$ & $290 \leq T_{m} \leq 574$ \\
PCM latent heat of fusion & $h_{\mathrm{sl}}$ & $\mathrm{kJ} / \mathrm{kg}$ & $106.5 \leq h_{s l} \leq 852.0$ \\
Zone height fraction & $H^{\prime}$ & - & $0 \leq H^{\prime} \leq 1$ \\
\hline \hline
\end{tabular}




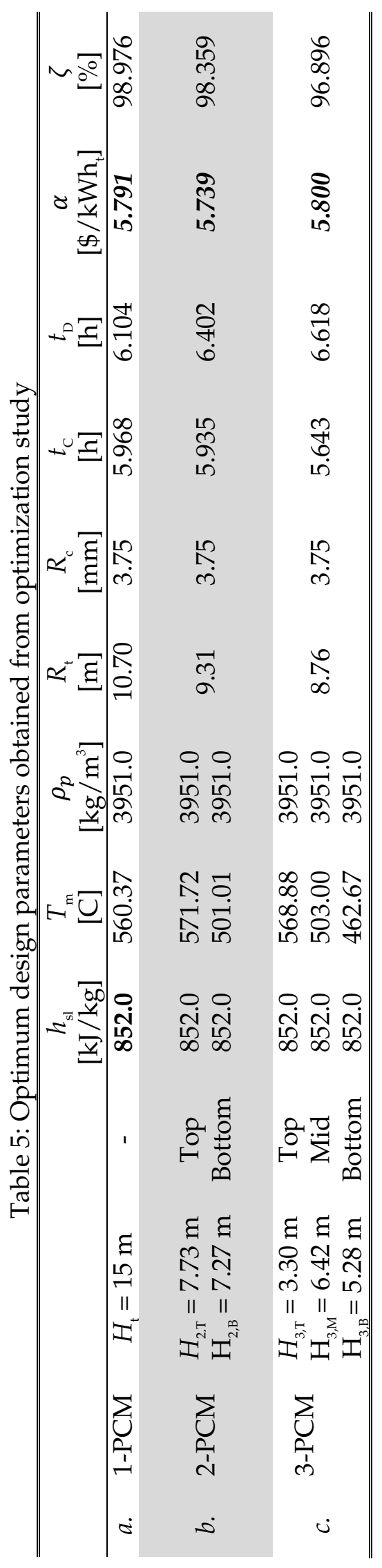




\section{Figure Captions}

Figure 1 Schematic illustration of: (a) encapsulated PCM thermal energy storage system (EPCM-TES), (b) capsule cross-section.

Figure 2 Effect of capsule radius on (a) charge and discharge time, (b) exergetic efficiency, and capacitance ratio on (c) charge and discharge time, (d) exergetic efficiency of non-cascaded EPCM-TES system for different Reynolds number. The lines with markers in Fig. 3a and 3c represent charge time and lines without markers indicate discharge time.

Figure 3 Effect of inverse Stefan number on (a) charge time, (b) discharge time and (c) exergetic efficiency, and PCM melt temperature on (d) charge time, (e) discharge time and (f) exergetic efficiency of non-cascaded EPCM-TES system for different Reynolds number.

Figure 4 Effects of (a) top zone PCM melt temperature, (b) bottom zone PCM melt temperature, and (c) top zone height of a 2-PCM cascaded EPCM-TES system on charge and discharge time for different Reynolds number. The lines with markers represent charge time and lines without markers indicate discharge time.

Figure 5 Effect of (a) top, (b) middle and (c) bottom PCM melt temperature, and (d) top, (e) middle and (f) bottom zone height of 3-PCM cascaded EPCM-TES system on charge and discharge time for different Reynolds number. The lines with markers represent charge time and lines without markers indicate discharge time.

Figure 6 Variation in storage cost with tank radius for different (a) capsule radius, (b) PCM latent heat of fusion and (c) PCM density for $15 \mathrm{~m}$ tall non-cascaded EPCM-TES system.

Figure 7 Effect of tank radius on (a) charge and (b) discharge time of $15 \mathrm{~m}$ tall EPCM-TES system, and (c) charge and (d) discharge time of $20 \mathrm{~m}$ tall EPCM-TES system.

Figure 8 Operating windows as functions of (a) capsule radius of $H_{t}=15 \mathrm{~m}$, (b) capsule radius of $H_{\mathrm{t}}=20 \mathrm{~m}$, (c) PCM latent heat of fusion of $H_{\mathrm{t}}=15 \mathrm{~m}$ and (d) PCM density for non-cascaded EPCM-TES system, and (e) bottom zone PCM melt temperature for 2-PCM cascaded, (f) bottom zone height for 3-PCM cascaded $15 \mathrm{~m}$ tall EPCMTES system. 


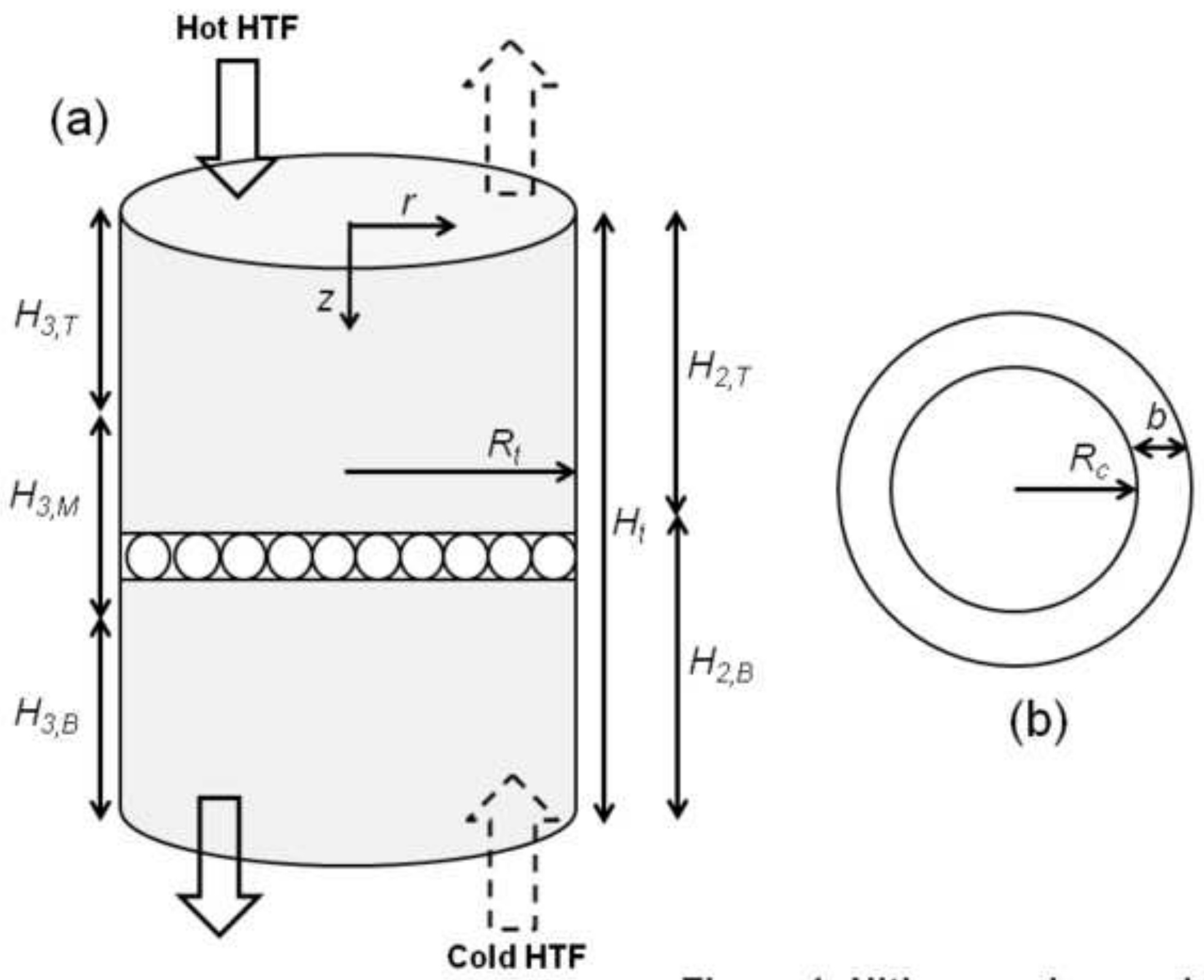

Figure 1, Nithyanandam and Pitchumani 


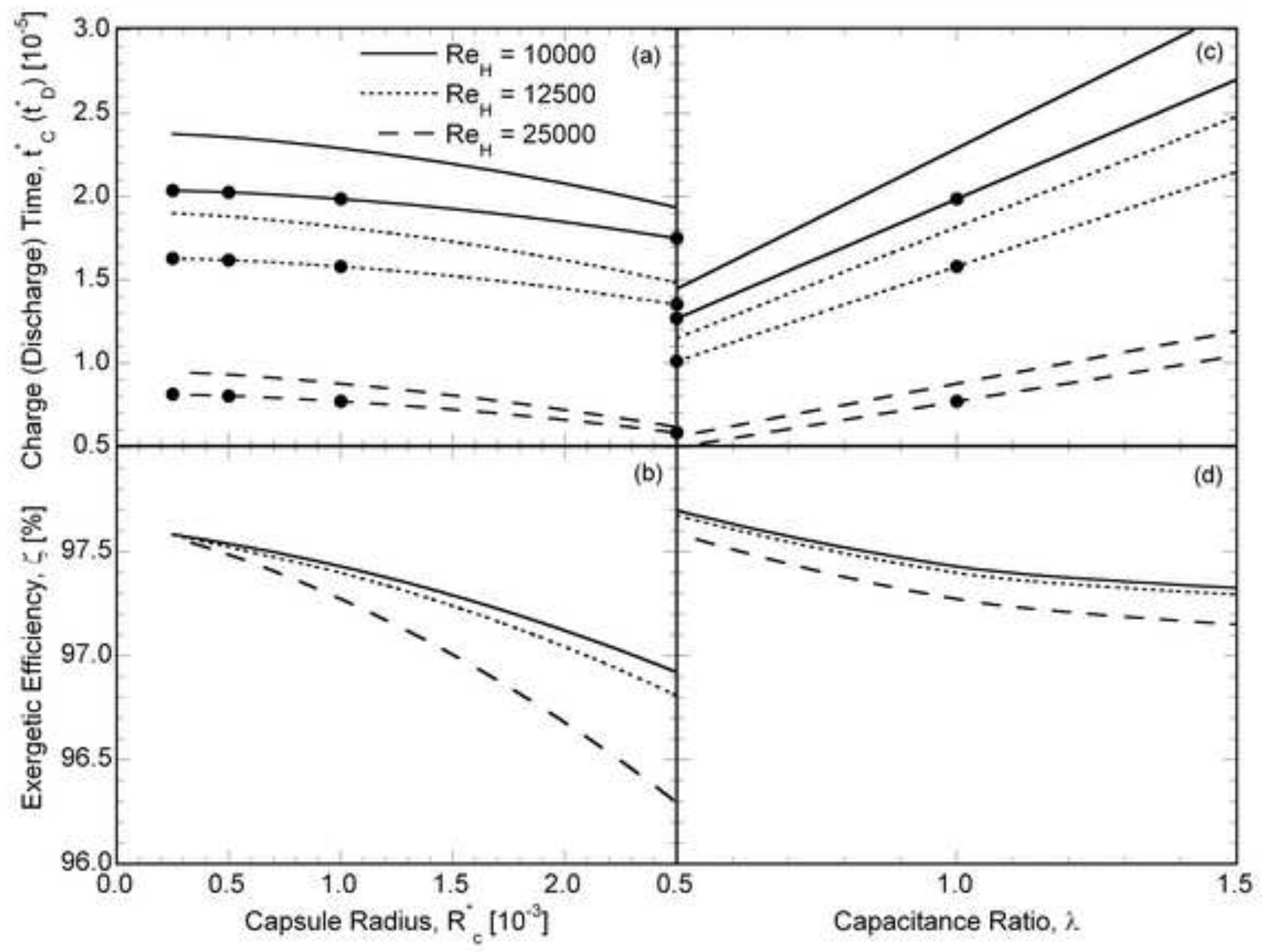

Figure 2, Nithyanandam and Pitchumani 


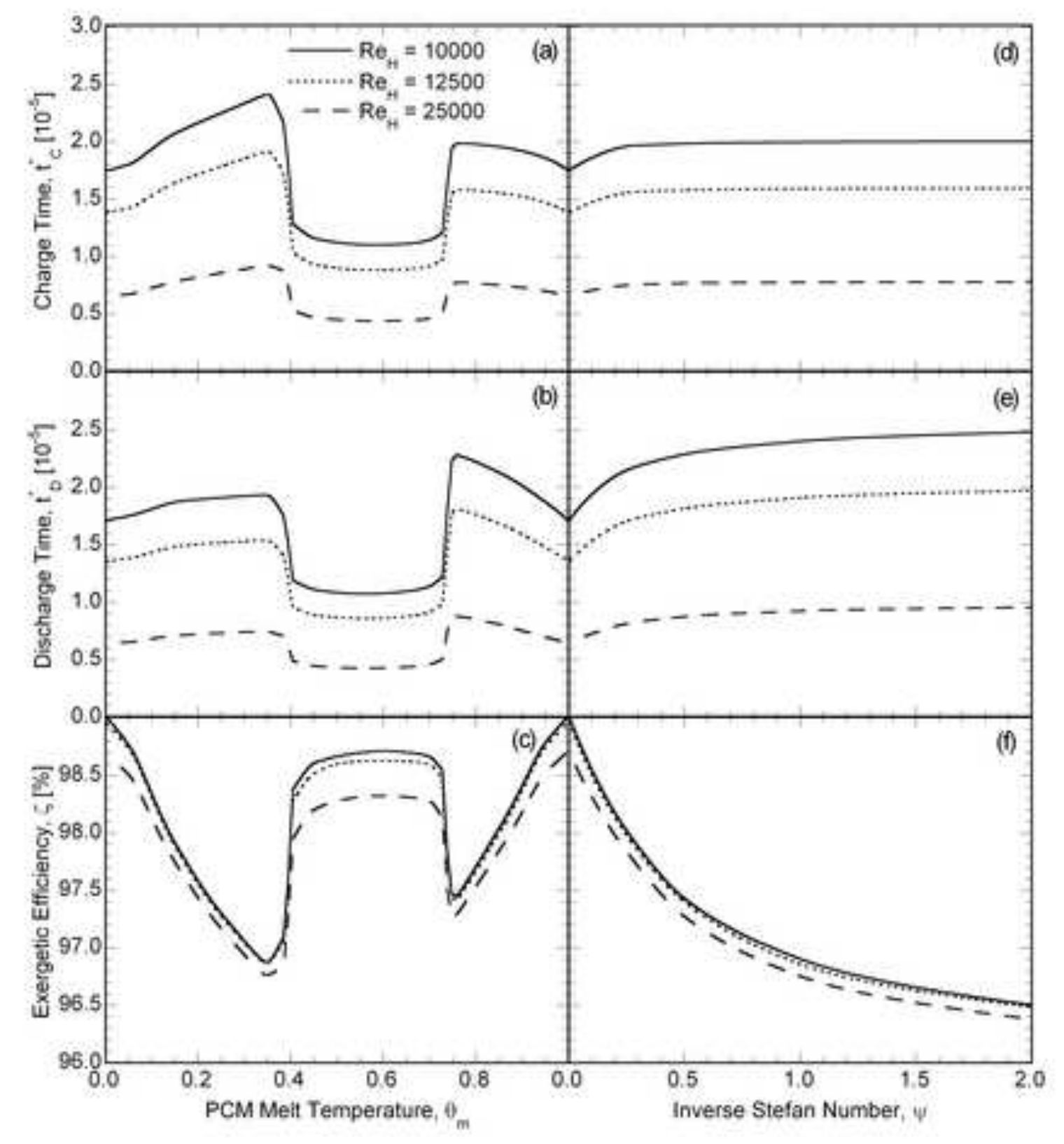

Figure 3: Nithyanandam and Pitchumani

Figure 3

Figure 3: Nithyanandam and Pitchumani

Figure

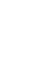

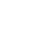

.

.
.
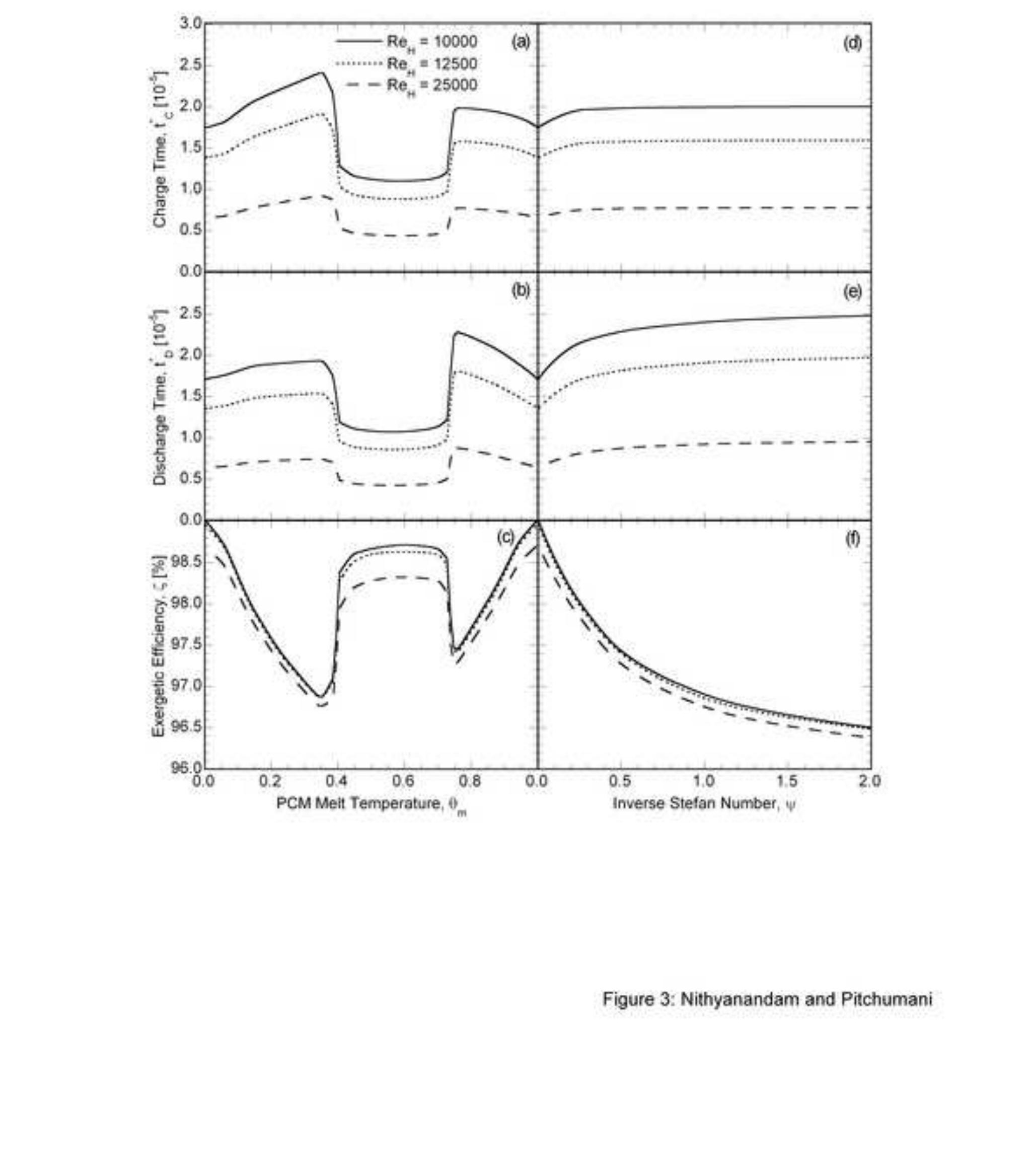

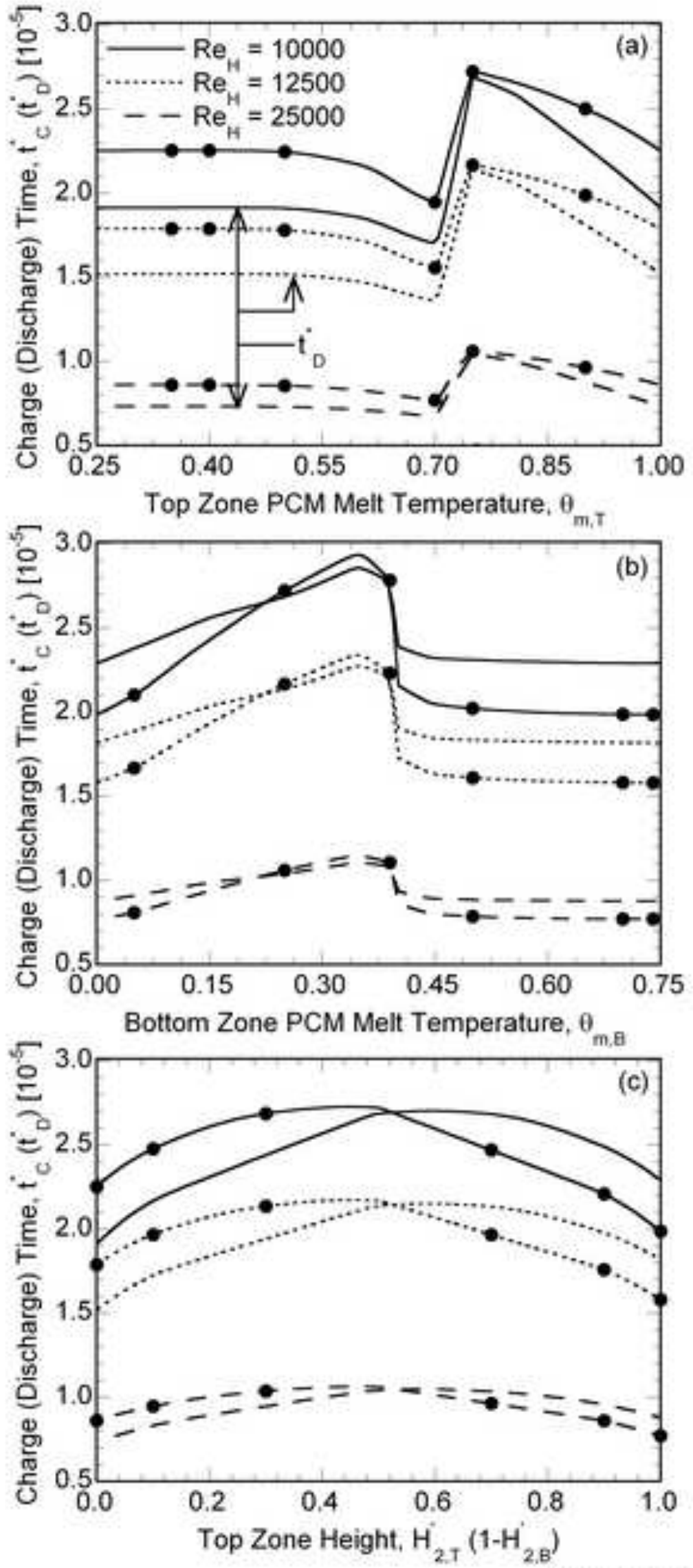

Figure 4: Nithyanandam and Pitchumani 

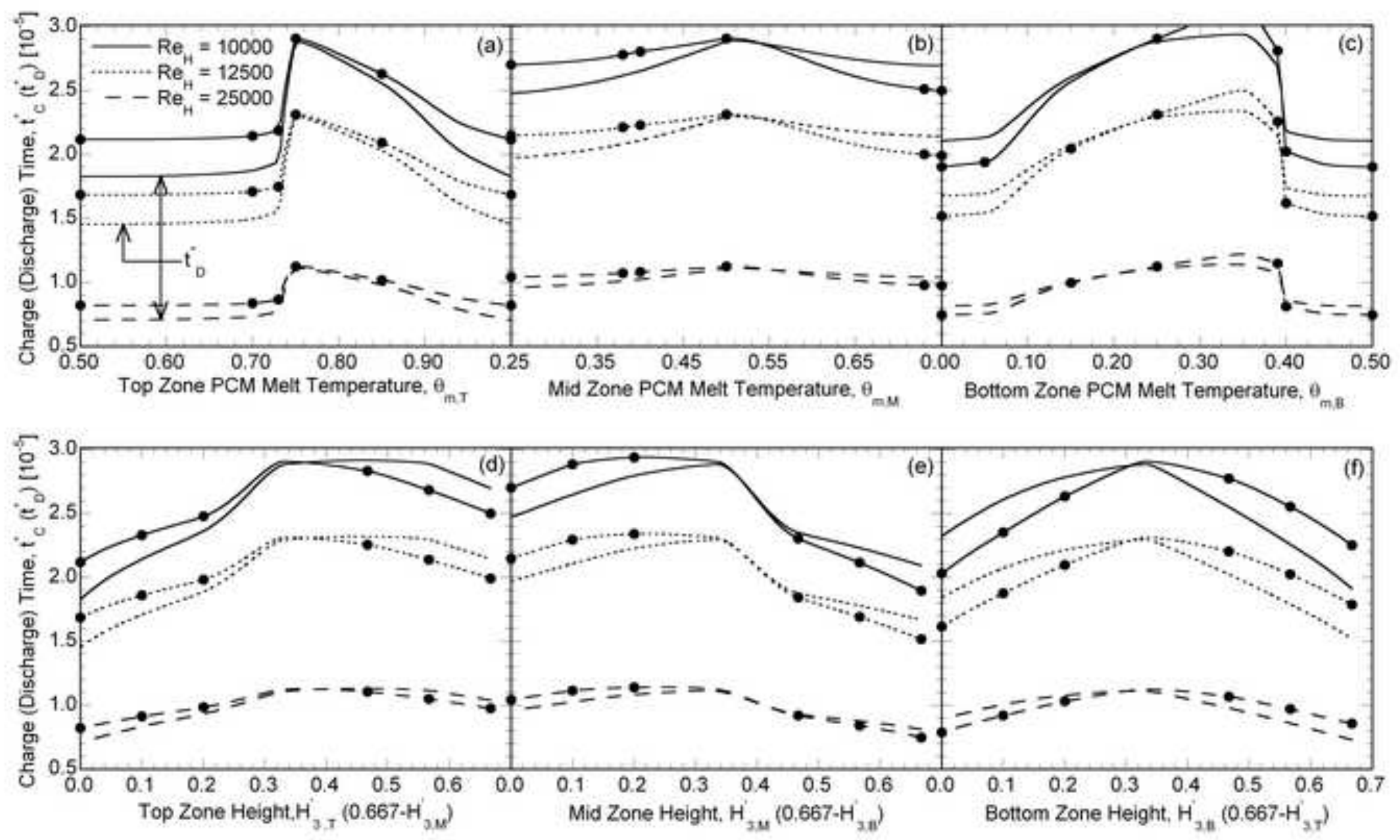

Figure 5: Nithyanandam and Pitchumani 


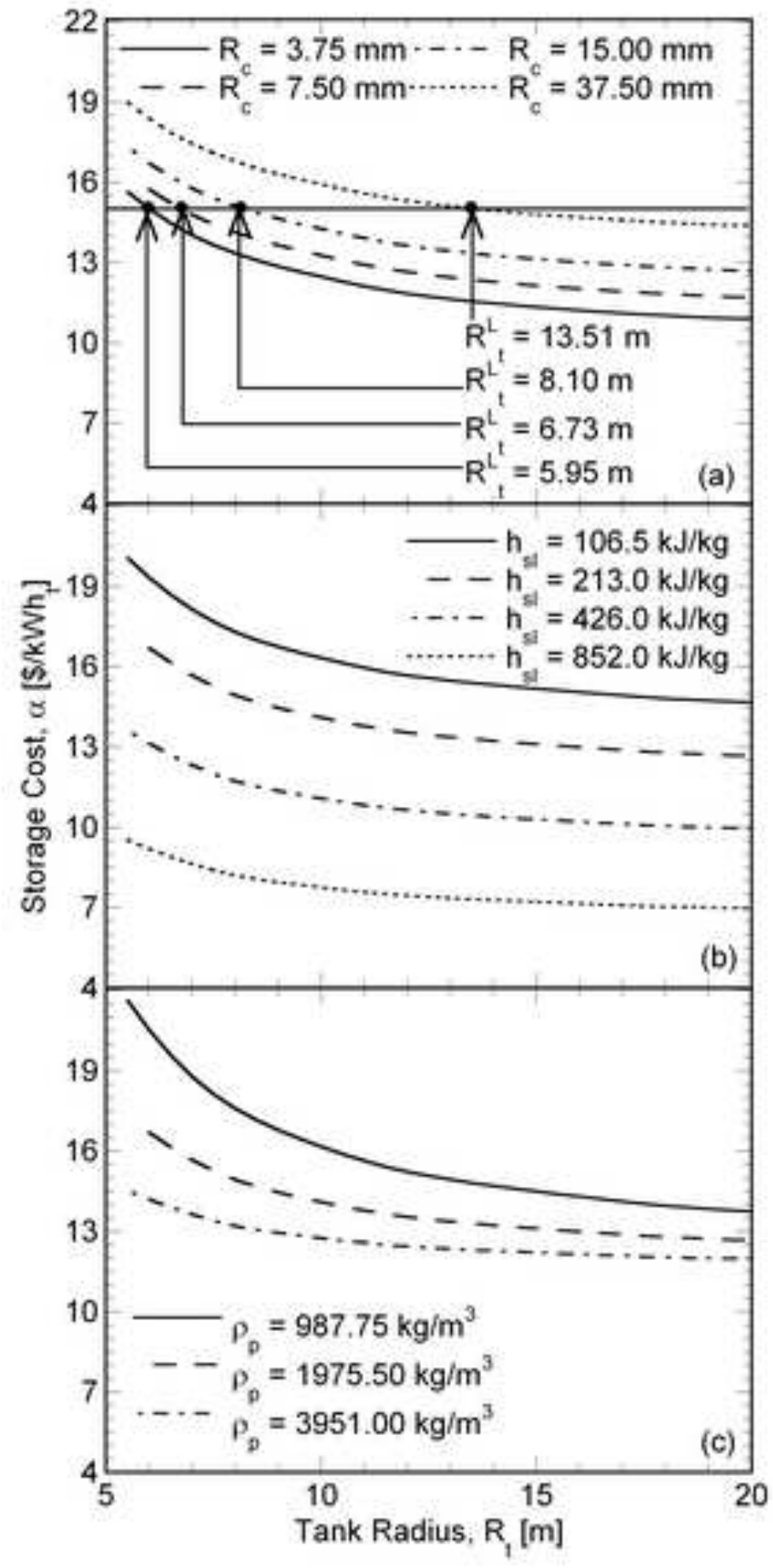

Figure 6: Nithyanandam and Pitchumani 


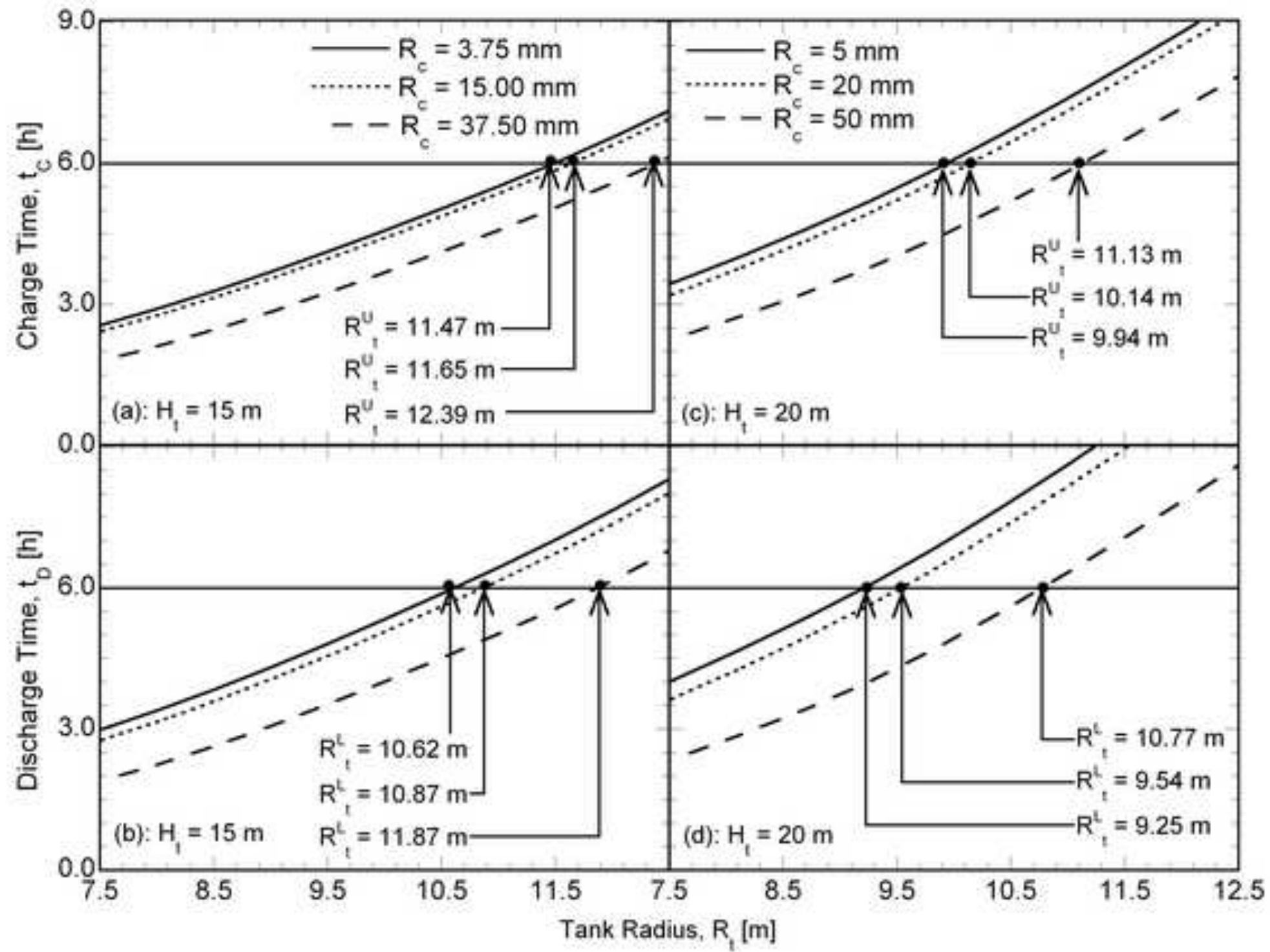

Figure 7, Nithyanandam and Pitchumani 

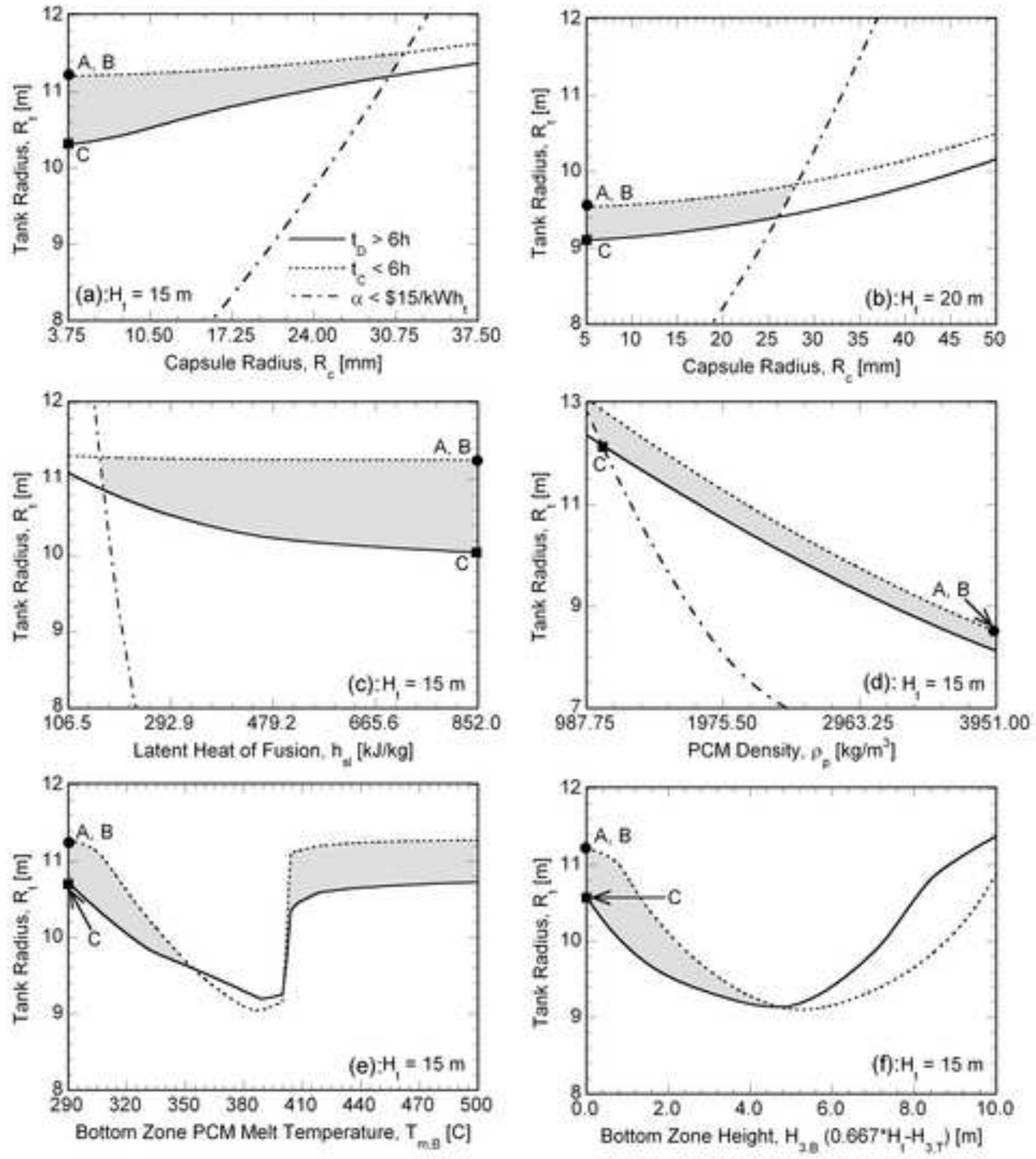

Figure 8: Nithyanandam and Pitchumani 